\title{
¿CÉsar contra Pompeyo? Nuevos hallazgos Para el ESTUDIO DE LA INSCRIPCIÓN $S C A E$ EN LAS GLANDES DE HONDA DE HISPANIA
}

\author{
Javier Moralejo Ordax \\ Universidad Autónoma de Barcelona \\ Juan Manuel SaAvedra \\ Universidad de Alcalá
}

Recibido: 08/09/2015

Revisado: 29/03/2016
Aceptado: $29 / 03 / 2016$

Publicado: 30/06/2016

\section{RESUMEN}

Estudiamos 11 proyectiles de honda de plomo procedentes de un área rural localizada $1,5 \mathrm{~km}$ al SE de la localidad de Huete, en la provincia de Cuenca. Las piezas pertenecen a una colección privada. El objetivo de este trabajo es identificar y analizar su tipología, y epigrafía a fin de averiguar su cronología, discernir las causas de su presencia en esta zona y aportar nuevos datos a la interpretación de las glandes de Hispania con la inscripción latina SCAE. ${ }^{1}$

\section{ABSTRACT}

We study 11 lead slingshot from a rural area located $1.5 \mathrm{~km}$ southeast from the town of Huete (province of Cuenca). The pieces belong to a private collection. The aim of this paper is to identify and analyze their type and epigraphy in order to find out their chronology, discern the causes of their presence in this area and provide new data to the interpretation of the glandes from Hispania with the Latin inscription SCAE.

\section{Palabras Clave}

glandes; huete; inscripción SCAE; bellum hispaniense; césar; pompeyo; sertorio.

\section{KEYWORDS}

slinshots; inscription SCAE; huete; bellum hispaniense; caesar; pompeius; sertorius.

javiersantiago.moralejo@uab.cat

javier.moralejo09@gmail.com

unganastis@gmail.com

1 Estudio llevado a cabo en el marco del Proyecto I+D: "Ab utilitate ad usum: los Tituli Antiqui en la definición de los territorios antiguos y su uso en la configuración de las entidades territoriales modernas”. FFI2012-39395-C02-01-02. 


\section{INTRODUCCIÓN}

El lugar de hallazgo de las piezas sometidas a estudio es el conocido yacimiento arqueológico del Cerro de Alvar-Fáñez. Se trata de un promontorio amesetado de unos $960 \mathrm{~m}$ de altura, que se alza sobre el valle situado entre los ríos Mayor y Aldehuela, a $1,5 \mathrm{~km}$ al SE de Huete (Cuenca, España). Presenta laderas escarpadas, especialmente en sus lados norte, sur y oeste, y mayor altura en su vertiente oeste (Castelo Ruano, 2008, 74-75). Su aspecto actual, concretamente el aplanamiento de la cúspide, podría deberse a los trabajos de cultivo que llevan realizándose en el cerro durante generaciones. El emplazamiento del cerro favorece, por otra parte, el asentamiento de una posición defensiva, pues sobresale de manera abrupta del territorio circundante. La comarca presenta un paisaje de meseta de una altitud media entre los 800 y $1000 \mathrm{~m}$, surcado por diversos cauces fluviales que han erosionado el terreno y levantado abruptas colinas. Esta submeseta se encuentra limitada por diversas cadenas montañosas que cruzan su territorio de norte a sur. La presencia de los ríos y sierras ha configurado las comunicaciones naturales de esta zona de tal manera que las vías de este a oeste resultan prácticamente inexistentes, mientras que, por el contrario, la comunicación en el eje norte-sur es relativamente fácil. Parece que el asentamiento humano en el área se concentró- a lo largo de la Edad del Hierro y el período romano- particularmente en torno a los valles y adoptó el eje norte-sur como vía de asentamiento y expansión, tal y como apuntan la investigación arqueológica llevada a cabo en el cerro de

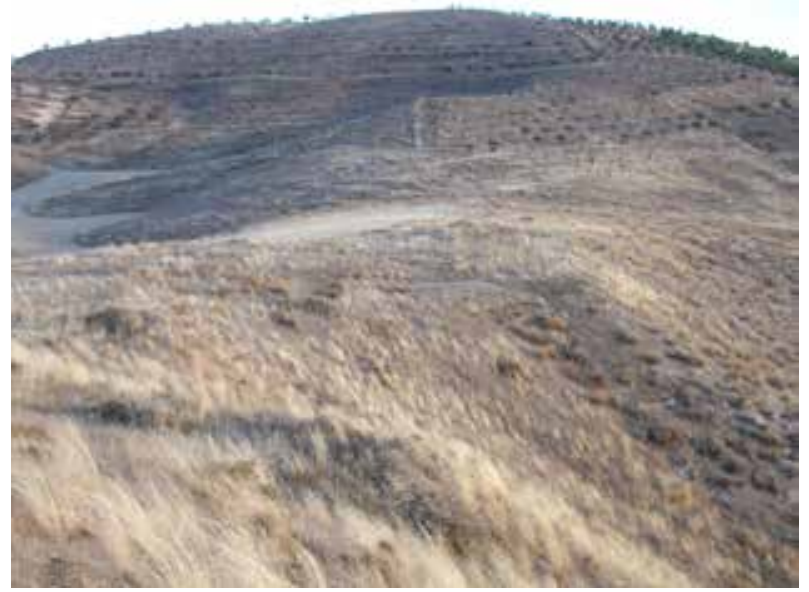

Figura 1. Vista de la ladera septentrional del Cerro de Alvar Fánez. Fotografía de los autores
Alvar-Fáñez y la prospección de sus inmediaciones (Castelo Ruano et alii, 2000, 95-149). Por otra parte, la posición estratégica del lugar y la constatación de su ocupación y fortificación, nos proporcionan un contexto a priori plausible para la presencia de proyectiles de honda en sus laderas (figura 1).

El yacimiento de Alvar-FÁÑEZ.

Las primeras excavaciones científicas del Cerro de Alvar-Fáñez, iniciadas en la década de los años 70 , del siglo pasado, pusieron de manifiesto una secuencia habitacional continuada de dicho enclave desde la I Edad del Hierro hasta la Antigüedad Tardía, siendo en el período alto-imperial cuando el asentamiento alcanzó su más alto nivel socio-económico gracias a la explotación de las minas de lapis specularis (Castelo Ruano et alii, 2000, 141, nota 1; Di Monti, Gómez, 2004, 245-256) (figura 2). El yacimiento presenta, pues, vestigios de hábitat continuado desde el Hierro I (800-500 a. C) definiéndose y evolucionando su ocupación en la II Edad del Hierro. Parece que los pueblos que habitaron este y otros asentamientos de las cercanías podrían vincularse culturalmente al ámbito de los celtíberos del sur de la Meseta. Siguiendo los testimonios de las fuentes literarias, habría que identificar a los habitantes de estos territorios con los Olcades, uno de los pueblos celtibéricos menos conocidos, asociados también a los oppida de Segobriga y Valeria, entre otros (Polyb. 3, 23, 2; Liv. 40, 50). M. Almagro Gorbea considera que los territorios de la actual Huete, partiendo de Carrascosa del Campo, pertenecerían, por el contrario, al ámbito de la Carpetania y sus gentes al sustrato cultural ibérico (Castelo Ruano et alii, 2000, 101; Almagro Gorbea, 1999, 25-48); en todo caso, a la luz de los testimonios arqueológicos, el cerro continuó habitado hasta la llegada de Roma. La comarca de Huete entró en contacto con el mundo Mediterráneo en el contexto de la II Guerra Púnica, cuando Aníbal penetró en territorio de los Olcades y conquistó su capital, al sur de la actual provincia de Cuenca. Los cartagineses fueron derrotados y expulsados en 206 a. C., y partir de entonces, hallamos indicios de los primeros elementos romanos en contacto directo con la comarca de Huete (Almagro Basch, 1978; Osuna Ruíz, 1997, 169-208). La pronta incorporación de esta zona al ámbito de influencia romano, favoreció la romanización de la comarca, de la que los restos arqueológicos del Cerro de Alvar-Fáñez son un testimonio temprano (Castelo Ruano et alii, 2000). 


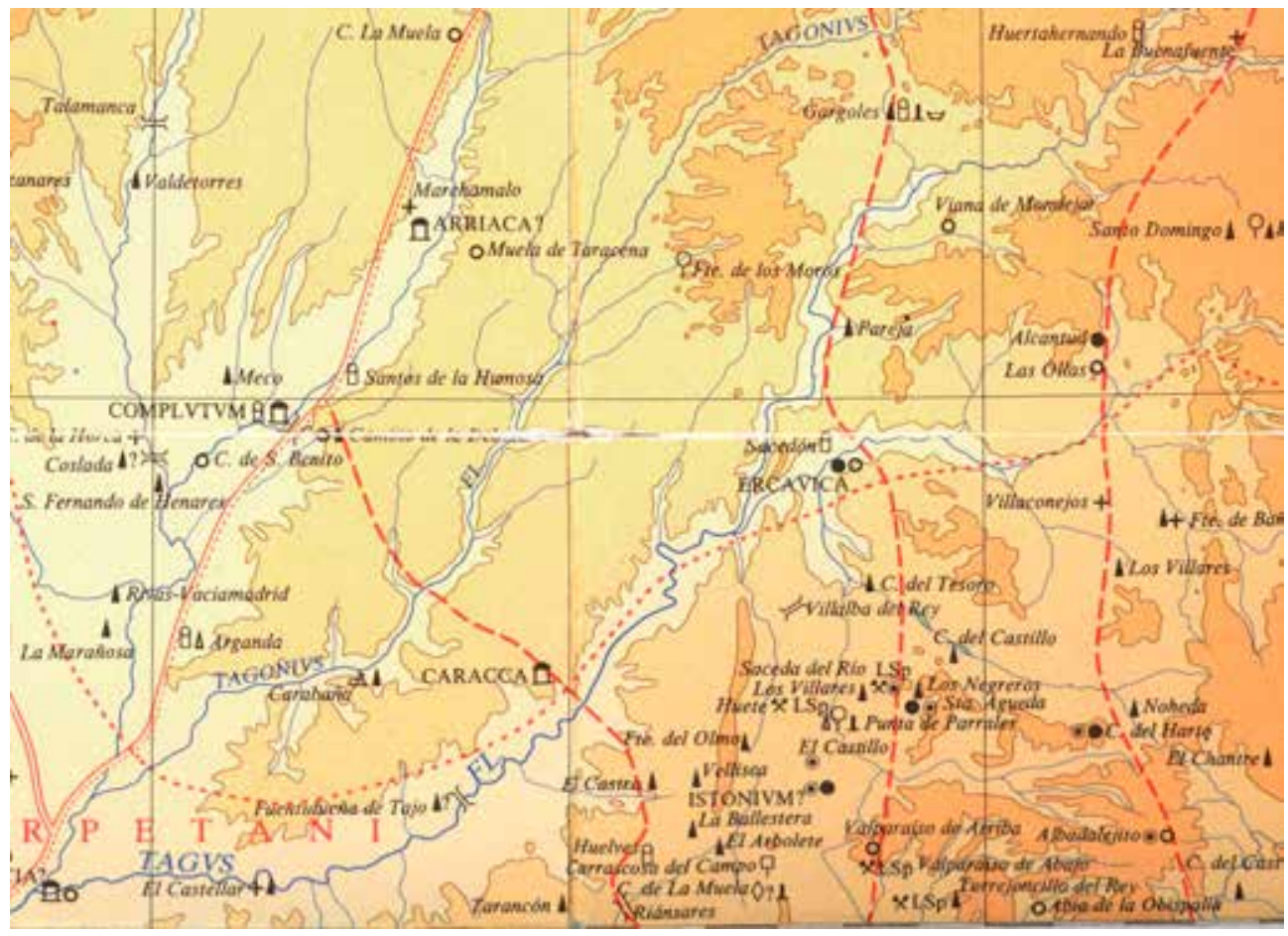

Figura 2. Localización de Huete (Istonium?). Según la TIR hoja J. 30 (Valencia).

Las excavaciones dieron a conocer una considerable cantidad de materiales, tanto cerámicos como pétreos, óseos y metálicos: fichas de juego de cerámica y piedra, piezas hechas en hueso como acus crinales (Aguado Molina et alii, 2007, 500)2, y numerosos objetos metálicos de bronce y de hierro (Castelo Ruano et alii, 2000, 132). El repertorio cerámico del Cerro de Alvar-Fáñez es igualmente rico y diverso tipológicamente: desde un fragmento de cerámica ática de figuras rojas (Castelo Ruano, 2008), campaniense, pintada ibero-romana, algunos vasos de paredes finas (Castelo Ruano et alii 2000, 120), así como diferentes modelos de terra sigillata gálica (Zarzalejos Prieto 2004, 161) e hispánica (Zarzalejos Prieto, 1994, 176, nota 22), entre los tipos básicos. Ello nos lleva a constatar un amplio marco cronológico de hábitat para el Cerro y revela que, antes de la conquista romana, sus pobladores ya mantenían contactos con el levante peninsular.

2 Entre los objetos metálicos realizados en bronce: una fíbula anular hispánica, una grapa con inscripción: "ARCILLVS", quizás el nombre del posible taller, agujas, un regatón de embocadura semicircular, un remate de empuñadura de espada o puñal etc. En hierro encontramos de nuevo elementos parecidos a los anteriores, como grapas de sujeción o una llave, entre otros.
LOS PROYECTILES DEL CERRO DE ALVAR-FÁÑEZ (HUETE, CUENCA) ESTUDIO TIPOLÓGICO: LIMITACIONES Y METODOLOGÍA

El lote de glandes localizado en Alvar-Fáñez, actualmente en manos de un privado, consta de 11 piezas de diversa morfología, que aparecieron, en el año 2010- todas ellas en un espacio que podemos acotar aproximadamente en unos $80 \mathrm{~m}^{2}$ - concentradas en las laderas septentrionales. A la luz de las informaciones recibidas, podemos asumir que los proyectiles pertenecen a un mismo contexto de hallazgo, que son auténticos, y que parecen constituir, desde un punto de vista arqueológico, un conjunto o lote que pertenece al mismo momento histórico. Todos son de plomo y uno de ellos tiene una inscripción latina.

En los estudios de este tipo de proyectiles (carentes de contexto arqueológico) es de vital importancia un análisis tipológico lo más detallado posible, en el que es preciso tener en consideración una serie de parámetros básicos: el material (plomo, barro cocido), medidas, peso, forma, inscripciones (si las hay) y otro tipo de marcas iconográficas, así como el estado de conservación. Dos de estos son especialmente significativos: el peso y la presencia de inscripciones, pues, la uniformidad morfológica de este tipo de artefactos y la ausencia de contextos 
claros, hacen de ellos los únicos criterios discriminatorios. En la Península Ibérica contamos con dos marcos históricos principales en los que encuadrar las glandes plúmbeas: la Segunda Guerra Púnica y las guerras civiles que libró Roma en el transcurso del siglo I a. C., y no es tarea fácil diferenciar las glandes anepígrafas pertenecientes a uno y otro período.

Para el análisis morfológico de las piezas, hemos recurrido a la clasificación de Völling, en la medida de lo posible, ya que las glandes plúmbeas son bastante homogéneas morfológicamente, lo que genera normalmente tipologías de corte general. Por ello nos topamos con ciertas limitaciones y escasa precisión para la inserción de nuevos ejemplares en los tipos de este repertorio. Conviene recordar, asimismo, que la homogeneidad de la que venimos hablando responde a una serie de aspectos que están vinculados con el artefacto en $\mathbf{s i}^{\prime 3}$. A todo ello habría que sumar otras cuestiones como el estado de conservación de la pieza y las señales y muescas debidas a su utilización: al tratarse de proyectiles no es nada raro comprobar que aparecen deformados por impactos. A pesar de todo, podemos incluir las piezas del Cerro de Alvar-Fáñez dentro de un horizonte tipológico y cronológico que se ajusta bastante bien al de otras piezas y colecciones conocidas y ya estudiadas que constituyen paralelos a tener en cuenta en relación con este conjunto.

CATÁLOGO DE PIEZAS": (figuras 3 y 4).

Número de Catálogo: 1. Longitud/Anchura (cm)/Peso (gr.):4,1/ 1,9/56

Clasificación (Völling): 2b (Völling, 1990, p. 34). Molde bivalvo

3 Las glandes de honda de plomo eran objetos cuya fabricación resultaba relativamente fácil, lo que permitía producirlas en grandes lotes para satisfacer las necesidades de munición de los ejércitos, incluso en momentos y situaciones particulares, como en el transcurso de la propia batalla. Se trataba de algo casi rutinario. A esto hemos de añadir otros condicionantes conocidos que dificultan la clasificación tipológica: el hecho de que se fabricaban en moldes en los que se fundían varias piezas a la vez, por lo que las morfologías tendían a uniformizarse a pesar de las variantes y de las taras en el proceso de fabricación. Por último, es preciso tener en cuenta la enorme dispersión de hallazgo de estas piezas: se han documentado proyectiles de honda a lo largo y ancho de todo el ámbito del Mediterráneo Antiguo, durante los períodos romano republicano e imperial.

4 Queremos agradecer a Luisa María Saldaña Puentes su generosa y desinteresada colaboración en el estudio tipológico, y documentación gráfica de los materiales que aquí presentamos.
Descripción: Presenta un cuerpo relativamente voluminoso, de gran anchura, y la morfología bicónica característica de los tipos del grupo 2 de Völling. Inscripción: SCAE. Altura de las letras: de $0,9 \mathrm{~cm}$. La marca se hizo en el momento de la fundición del plomo para el proyectil. La "S" está deteriorada en la parte superior y aparece una incisión posterior a las letras, tal vez por deterioro, o bien por el golpeo de la pieza con algún objeto. Las letras destacan en bajo-relieve sobre la superficie de la pieza. Se trata de capitales de factura tosca y considerable grosor. La pieza tiene una gran muesca longitudinal detrás de la letra $\mathrm{E}$, y otra de trayectoria diagonal en su extremo derecho en la parte inferior. Todas las muescas tienen aspecto de haber sido hechas al contacto de la pieza con instrumentos de labranza, como un arado.

Número de Catálogo: 2. Longitud/Anchura (cm)/Peso (gr.):4,1/1,8/43

Clasificación (Völling):1c

Descripción: Presenta su cara inferior plana con leve rehundimiento en su parte central. Fue fabricada en un molde univalvo, al igual que el resto de ejemplares que recogemos en este catálogo, excepto los números 1, 9 y 11. Es notable una gran muesca presente en uno de sus extremos. El aplanado de una de las caras del proyectil, hecho que se repite en varios ejemplares de nuestra serie, cuenta con paralelos en otros proyectiles hallados en suelo peninsular. Tal vez, la razón de que tengan esta morfología sea lo apresurado de su fabricación

Número de Catálogo: 3.Longitud/Anchura (cm)/Peso (gr.): 3,6/ 1,8/56

Clasificación (Völling): 1c. Molde univalvo

Descripción: Presenta su cara inferior plana con leve rehundimiento en la zona central y ambos extremos atrofiados, lo que puede deberse al impacto del proyectil, a su reutilización repetida, o bien al desgaste gradual de la pieza. No obstante, su forma en planta remite al horizonte del grupo 1c de Völling. Cabe destacar su reducida longitud y una muesca significativa en uno de sus lados que parece debida al golpeo de un objeto como el arado.

Número de Catálogo: 4 . Longitud/Anchura (cm)/Peso (gr.):3,7/1,7/37

Clasificación (Völling):1c Molde univalvo

Descripción: Presenta su cara inferior plana con leve rehundimiento en la zona central. Uno de 

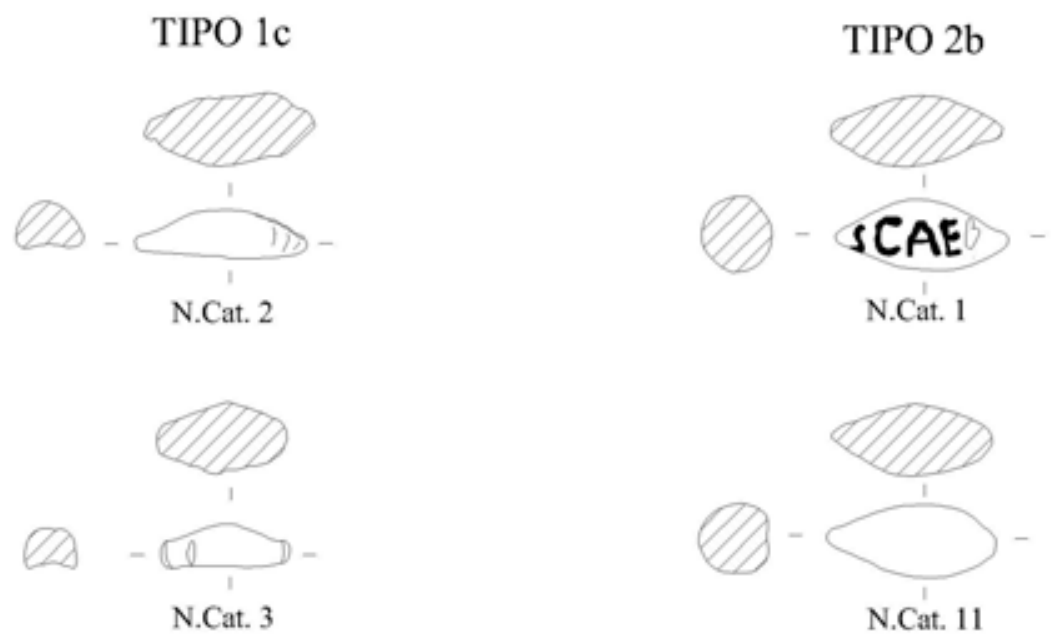

N.Cat. 3
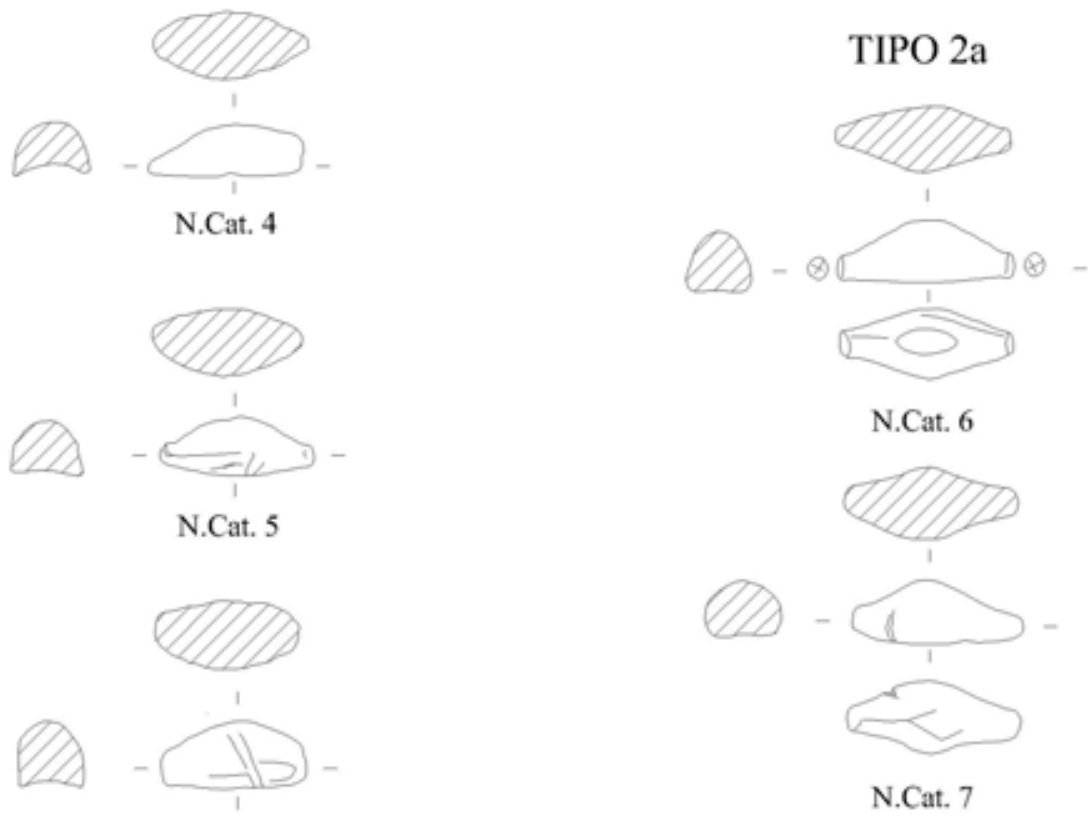

N.Cat. 8

N.Cat. 7

INDETER.

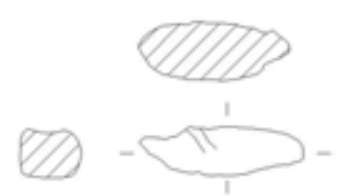

N.Cat. 10
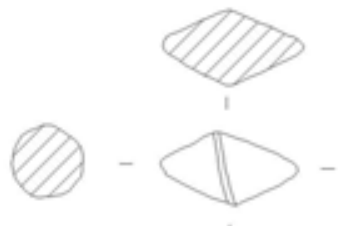

N.Cat. 9

Figura 3. Tipología del lote de glandes del Cerro de Alvar Fañez (Huete). Dibujo de L. M. Saldaña Puentes. 


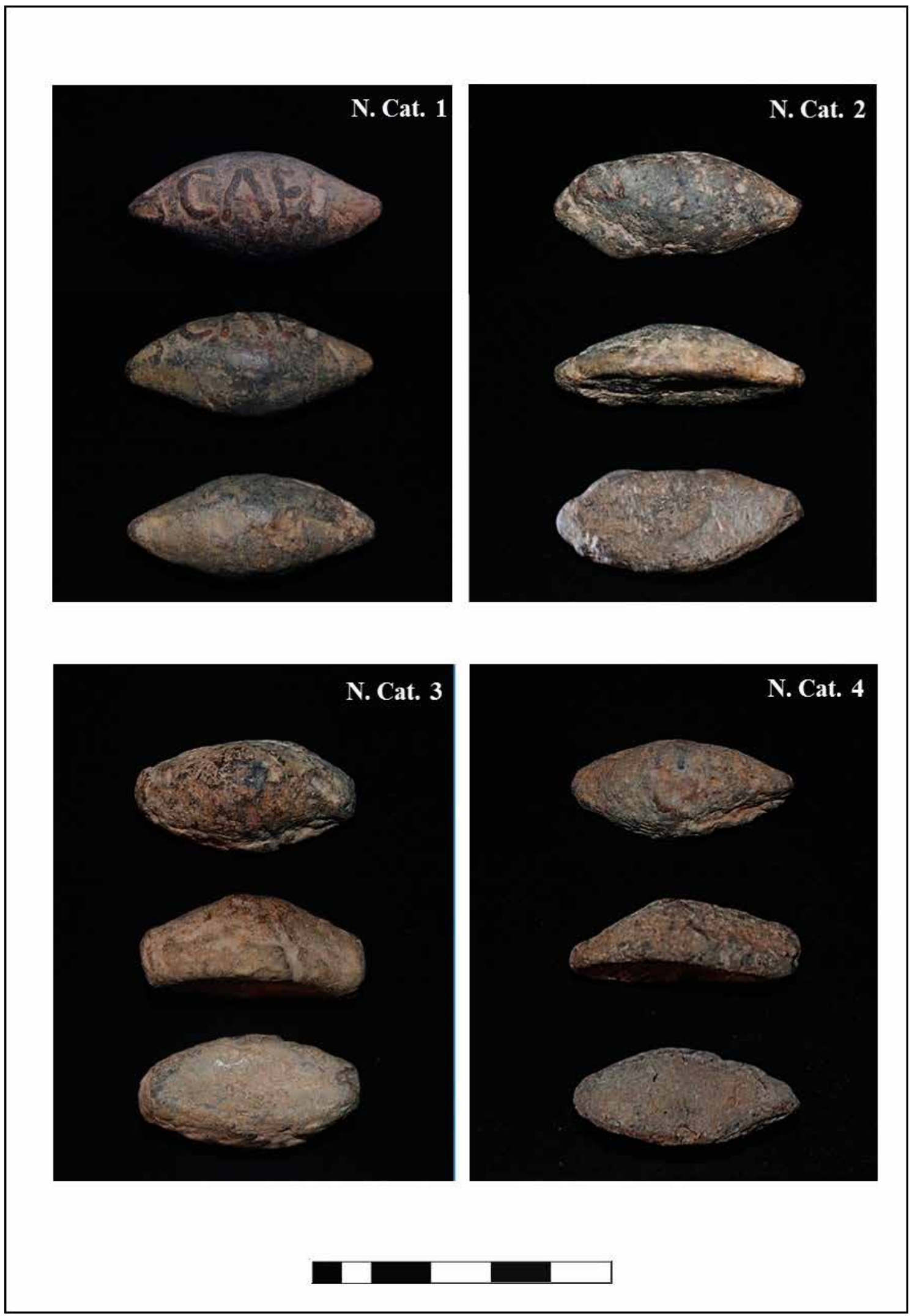

Figura 4. Fotografía de L. M. Saldaña Puentes y J. Moralejo Ordax. 
los extremos, el izquierdo, es apuntado, mientras que el otro parece más bien redondeado. El proyectil tiende a la morfología "naviforme", lo que nos mueve a incluirlo en el subtipo 1c de Völling.

Número de Catálogo: 5. (Fig. 5). Longitud/ Anchura (cm)/Peso (gr.):3,8/ 1,7/40

Clasificación (Völling): Indeterminada. Molde univalvo

Descripción: Presenta rasgos de deterioro llamativamente similares a los del ejemplar n. 4. Su cara inferior está aplanada con un ligero rehundimiento en la zona central, tiene una gran muesca en la zona inferior derecha de una de sus caras. Su extremo derecho se encuentra atrofiado posiblemente por haber impactado contra una superficie.

Número de Catálogo: 6. Longitud/Anchura (cm)/Peso (gr.):4,1/1,6/50

Clasificación (Völling):2a Fabricación en molde univalvo.

Descripción: De nuevo encontramos una de sus caras planas, pero en esta se observa una especie de incisión de morfología romboidal que parece practicada intencionadamente. Ambos extremos están claramente seccionados con un corte limpio, tal vez resultado del uso de una cizalla al extraer la pieza del molde. Presenta una marca en forma de $\mathrm{X}$ incisa en uno de los extremos rematados. No podemos saber si se trata de una marca practicada después de su fabricación o posteriormente. Fue elaborada en molde univalvo.

Número de Catálogo: 7. Longitud/Anchura (cm)/Peso (gr.): 4,1/1,9/49

Clasificación (Völling):2a. La tendencia de ambos extremos a la forma bicónica nos llevan a incluirlo en este subgrupo, aunque no sin reservas.

Descripción: Tiene una de sus caras plana, ambos extremos redondeados, uno de ellos tal vez por un impacto, y cuatro muescas marcadas: en la parte inferior, una marca romboidal idéntica a la de la pieza n.6. En su parte superior, a la altura de uno de los extremos de la pieza, se nota una descamación del plomo, probablemente producto del impacto de la bala contra alguna superficie. Fue fabricada en molde univalvo

Número de Catálogo: 8. Longitud/Anchura (cm)/Peso (gr.):2,9/1,6/23

Clasificación (Völling):1c. Molde univalvo
Descripción: Se trata del ejemplar de menores dimensiones de todo el lote. Tanto sus dimensiones como su peso son significativamente menores a la media del resto de piezas. Una de sus caras es plana y ambos extremos de nuevo aparecen significativamente atrofiados. De nuevo han sido cortados de manera limpia, aunque su extremo derecho está abollado y presenta una pequeña rebaba característica de las piezas que han impactado con una superficie dura. Cabe señalar también una notable muesca en su parte inferior.

Número de Catálogo: 9. (Fig. 6). Longitud/ Anchura (cm)/Peso (gr.):3,2/1,9/40

Clasificación (Völling):3

Descripción: Por los rasgos morfológicos de esta pieza: cuerpo bicónico con terminaciones apuntadas, debemos situarlo en un horizonte distinto a la mayoría de las piezas estudiadas. Este pertenecería quizá al tipo 3 , pero con una marca central como punto de unión de ambos lados que presentan extremos afilados. El lado izquierdo cuenta con un notable desgaste en la parte del extremo del proyectil. La factura del proyectil es defectuosa ya que sus extremos no casan de manera uniforme; ello podría ser debido a una fabricación apresurada.

Número de Catálogo: 10. Longitud/Anchura (cm)/Peso (gr.):3,9/1,4/36

Clasificación (Völling): Indeterminada. El proyectil está muy deformado, probablemente debido a impactos como consecuencia de su utilización. No es posible una asignación tipológica. Molde univalvo.

Descripción: Es el ejemplar que se conserva en peores condiciones. En este caso sus dos caras son planas, observándose en una de ellas una muesca notable y pérdida parcial del volumen de su parte inferior.

Número de Catálogo: 11. Longitud/Anchura (cm)/Peso (gr.):4,1/1,6/1,8/56

Clasificación (Völling):2b bivalvo

Descripción: Se trata de un tipo muy similar al n.1 del catálogo, aunque esta vez anepígrafo. Está fabricada con molde bivalvo y se aprecia alguna rebaba en el punto de unión de ambos caparazones. Presenta señales de degaste evidentes en su extremo izquierdo y una gran muesca en su parte central, quizá como consecuencia de algún impacto o bien del golpeo del arado u otro instrumento del estilo. 


\begin{tabular}{|l|l|l|l|l|}
\hline \multicolumn{2}{|l|}{ Tabla 1. Resúmen de valores de las glandes de Alvar-Fáñez } \\
\hline CATÁLOGO & ANCHURA $(\mathrm{cm})$ & LONGITUD $(\mathrm{cm})$ & PESO: $(\mathrm{gr})$ & $\begin{array}{l}\text { TIPOLOGÍA } \\
\text { (Völling) }\end{array}$ \\
\hline 1 & 1,9 & 4,1 & 56 & $2 \mathrm{~b}$. \\
\hline 2 & 1,8 & 4,1 & 43 & 1c. \\
\hline 3 & 1,8 & 3,6 & 56 & 1c \\
\hline 4 & 1,7 & 3,7 & 37 & $1 \mathrm{c}$ \\
\hline 5 & 1,7 & 3,8 & 40 & $1 \mathrm{c}$. \\
\hline 6 & 1,6 & 4,1 & 50 & $2 \mathrm{a}$ \\
\hline 7 & 1,9 & 4,1 & 49 & $2 \mathrm{a}$ \\
\hline 8 & 1,6 & 2,9 & 32 & $1 \mathrm{c}$ \\
\hline 9 & 1,9 & 3,2 & 40 & 3 \\
\hline 10 & 1,4 & 3,9 & 36 & Indeterminada \\
\hline 11 & & & 56 & $2 \mathrm{~b}$ \\
\hline- & ANCHURA & LONGITUD & PESO MEDIO & - \\
\hline- & 1,73 & 3,75 & 45 & - \\
\hline
\end{tabular}

Los 11 ejemplares analizados presentan pesos diversos y bastante heterogéneos. En lo referente a sus dimensiones, son relativamente parejos en anchura pero no en longitud. La adscripción morfológica a los tipos de Völling resulta compleja pero atiende a criterios generales relativamente fiables. Son claros los números 1 y 11 y contamos con otros cuatro ejemplares que parecen poder incluirse en el tipo 1c. Por último, la n. 6 y n. 7 podrían considerarse dentro del grupo 2 a de Völling, con una morfología marcadamente romboidal, más definida en la n.6, con los extremos achatados. En la n. 6 y la n. 7 se nota un rehundimiento en su parte inferior que se asemeja a los documentados en ejemplares, en los lotes recuperados en Monzón (Huesca), concretamente el n. 61 del catálogo de Contreras et alii, $\mathrm{y}$ otro de la única glande publicada del conjunto inédito del yacimiento de Sanitja, del que daremos cuenta más adelante (Contreras et alii, 2006-2007, 10, n. 61, fig. 3).

A pesar de su heterogeneidad, las balas de Huete, cuentan, algunas de ellas, con ciertas características comunes: ocho de los once proyectiles estudiados están realizados en molde univalvo, y, tan sólo el n. 1, el n. 9, y n. 11 difieren en este aspecto del resto del lote. Estos ocho ejemplares, presentan otra característica en común: sus caras inferiores están aplanadas, seis de ellos presentan un ligero rehundimiento en la parte central de esta cara inferior, y otros dos, sendas incisiones de forma romboidal. El rehundimiento de la parte inferior de las piezas arriba mencionadas, parece ser un rasgo especialmente común en algunos ejemplares del siglo I a. C. Por lo demás, la mayoría del conjunto, en especial los números 2 al 5, 8, 10 y 11 presentan marcadas señales (incisiones o extremos rematados) a causa de impactos de uso, o bien por haber sido golpeados posteriormente por instrumentos como un arado. Por último, la glande n. 5 presenta un pequeño orificio de morfología irregular y profundidad considerable que podríamos achacar a un defecto de fabricación al verter el plomo fundido o extraer la pieza del molde. A pesar de las marcas de uso y defectos, no consideramos que ninguno de ellos haya perdido una parte significativa de su forma y peso originales.

La media de pesos de las 11 piezas de Huete es de $45 \mathrm{~g}$, valor que no coincide con el peso exacto de ninguno de los once ejemplares del catálogo. El 
reducido número de ejemplares y su variabilidad, no nos permite trabajar con intervalos con una garantía de representatividad estadística con la que extraer datos de utilidad para comparar con otros conjuntos. Nos limitaremos pues, a una comparativa general de la media de pesos con otras documentadas en conjuntos de Hispania.

GLANDES PLÚMBEAS EN HISPANIA: HACIA UN CONTEXTO HISTÓRICO Y CRONOLÓGICO DEL CONJUNTO DE ALVAR-FÁÑEZ

La mayor parte de los trabajos sobre las glandes habidos en España (Pemán 1988, 35-80; García, Lalana 1991, 101-107; Quesada Sanz, 1997; Aranegui Gascó, 2003; Díaz Ariño, 2005; Stylow 2005, 257-258; 262; Fontenla Ballesta 2005, 67-84; Pina y Zanier, 2006) ${ }^{5}$, se han centrado en analizar, datar y sistematizar conjuntos de estas balas hallados en zonas arqueológicas (no en excavaciones científicas ni en contextos fechables) o bien, reunidos en colecciones privadas, provenientes, la mayor parte, de actividades clandestinas. Sin embargo, tenemos también a nuestra disposición una serie de estudios de enfoque más amplio que han abordado aspectos

5 Para los proyectiles de honda en la Península Ibérica son de consulta obligada: Quesada Sanz, 1997 que sigue siendo el estudio más detallado de las piezas consideradas prerromanas; Díaz Ariño, 2005, que recoge 101 glandes con inscripción publicadas de la Península Ibérica, pertenecientes a las guerras civiles romanas del siglo I a. C. Presenta, además, una minuciosa sistematización y división de los ejemplares pertenecientes a las guerras de Sertorio y las de César y Pompeyo con mapas actualizados de distribución de ejemplares inscritos. Se trata del trabajo, a nuestro juicio más completo sobre los proyectiles de honda hispanos. Aranegui Gascó , 2003. Esta autora (2003, p. 51) considera dos posibilidades para la datación de los cinco proyectiles plúmbeos con inscripción griega del Museo Británico supuestamente procedentes de Sagunto. La primera hipótesis aboga por la posibilidad de que hubiera honderos griegos en las tropas de los Escipiones que recuperaron la ciudad de Sagunto entre el 214 y el 211 a. C. La segunda posibilidad sería la adscripción local (a Sagunto) de las piezas, lo que evidenciaría los fuertes contactos del lugar con el mundo griego y su apertura al mundo mediterráneo. Esta última opción parece menos probable. Por su parte, Quesada Sanz $(2007,176)$, considera la II Guerra Púnica y el mercenariado ibérico al servicio de Aníbal como contexto más probable de dichas piezas. Pina Polo-Zanier, 2006. Dan a conocer 49 glandes, conservados por un coleccionista privado, supuestamente provenientes del Cerro de las balas, que se ha venido identificando con el escenario de la batalla de Munda. Pemán, 1988, 35-80; García-Lalana, 1991, 101-107; Stylow, 2005, 257-258; 262; Fontenla Ballesta, 2005, 67-84. como la morfología, distribución, peso, fabricación y utilización en distintas zonas y franjas cronológicas, para tratar de dar una respuesta de conjunto a los problemas derivados del estudio de estas piezas (Hubrecht, 1964; Henry, 1975-76; Henry, 1976; Greep, 1987; Griffith, 1989; Völling, 1990; Domínguez Monedero, 2005; Planas, Madrid, 1994; Quesada Sanz, 1997) ${ }^{6}$.

En lo concerniente a los hallazgos del período pre-romano en la Península Ibérica, P. Moret y C. Aranegui, mantienen que, a pesar de la escasez de contextos arqueológicos, existen indicios para afirmar la introducción de las glandes plúmbeas en Iberia a lo largo del siglo IV a. C., mediante contactos con griegos e itálicos. Dichos contactos se habrían intensificado de manera significativa con ocasión del inicio de la II Guerra Púnica (Moret 1996; Aranegui Gascó, 2003, 50). A partir del inicio del conflicto, la presencia de socii itálicos y de mercenarios griegos, con tropas de honderos en las filas romanas habría difundido el uso de la honda y las balas de plomo en parte del territorio ibérico peninsular. Por nuestra parte, suscribimos la argumentación de Quesada cuando afirma que: "un estudio somero del catálogo de glandes demuestra que, aparte de ser poco frecuentes (y verdaderamente raras en los ss. V-III a.C. en el área ibérica), son sistemáticamente piezas tardías" (Quesada Sanz 1997, 475-480; 922-924.) Sin embargo, es preciso tener en cuenta aquí los recientes hallazgos de la excavación arqueológica del Cerro de las Albahacas (Santo Tomé, Jaén) a cargo del equipo del Proyecto Baecula. Las piezas encontradas en el cerro de las Albahacas son balas plúmbeas, las primeras exhumadas con métodos científicos, y bien contextualizadas y permiten, junto con los demás hallazgos de objetos del equipamiento militar de los soldados, documentar con claridad fases del combate entre romanos y cartagineses en el contexto de la batalla de Baecula, en el 209 a. C. (Ruiz et alii, 2011)

6 Casi todos estos estudios se han centrado en el ejército romano como gran aglutinador de tropas de honderos. El más destacado de estos análisis de conjunto es el que emprendió Völling (1990). Son asimismo destacables: Griffith, 1989, de nuevo en el contexto de tropas auxiliares en el ejército romano, tanto republicano como imperial; Hubrecht, 1964; Greep, 1987.

Para el uso de la honda en contextos ajenos al ejército romano: Henry, 1975-76; Henry, 1976. Para la problemática vinculada a la honda y honderos baleáricos: Domínguez Monedero, 2005; Planas, Madrid, 1994; Quesada Sanz, 1997.

7 Durante el proceso de publicación de este trabajo han 
Datados en fechas algo más tardías, contamos con otros conjuntos pre-romanos destacables como el lote de 41 piezas anepígrafas del yacimiento ibérico del Puntal dels Llops (Olocau, Valencia), fechable a comienzos del siglo II a. C, o las 1400 de plomo -también anepígrafas- halladas en Ampurias (Puig i Cadafalch, 1911-1912), datadas a mediados del siglo II a. C (Bonet Rosado, Mata-Parreño, 2002). Dentro de este catálogo, habría que incluir, por criterio cronológico, las cinco piezas con inscripción griega de Sagunto estudiadas por C. Aranegui, aunque estas sí presentan inscripciones (nota 21).

El estado actual de nuestros conocimientos, nos permite fechar las primeras glandes plúmbeas, todas ellas anepígrafas, documentadas en la Península Ibérica en el período de la Segunda Guerra Púnica, y confirma la difusión de su empleo y la aparición de glandes inscriptae (en griego e ibérico) a lo largo del siglo II a. C, especialmente en el área levantina del territorio ibérico. No obstante, la inmensa mayoría de los ejemplares documentados son de época de las guerras civiles romanas que tuvieron Hispania como teatro de operaciones. Dentro de los conjuntos de este período, los ejemplares que más importan a la reconstrucción histórica son aquellos que incorporan inscripción, hasta el punto de que, en muchos casos y sometidos al debido análisis epigráfico, aportan datos concluyentes sobre la datación y contextualización de los conjuntos. A partir del siglo I a. C, aparecerá la costumbre de añadir inscripciones latinas con diversos tipos de mensajes en el cuerpo de las balas. La aparición de las glandes con inscripción en Hispania está estrechamente vinculada con el hábito de emplearlas como soporte de mensajes de tipo político -a modo de propaganda- en un contexto bélico de enfrentamiento entre romanos (Díaz Ariño, 2005, 231, entre otros). Se trataba de un medio muy eficaz y poco costoso para plasmar los mensajes y hacerlos llegar. El hecho de estar redactados en latín, sugiere, tal y como apunta Díaz Ariño, que los principales usuarios de las glandes inscriptae eran los propios soldados regulares de la legión romana, que leían latín, y no las tropas

visto la luz un trabajo de gran relevancia que no hemos podido revisar: Quesada Sanz, F; Gómez Cabeza, F; Molinos Molinos, M y Bellón Ruiz, J.P., (2015), "El armamento hallado en el campo de batalla de Las Albahacas-Baecula", en, J.P. Bellón et al. (Eds.): La Segunda Guerra Púnica en la Península Ibérica. Baecula, arqueología de una batalla, Jaén. auxiliares (Díaz Ariño, 2005, 231). Sin embargo, no está tan clara la cuestión de los destinatarios de dichos mensajes. Se suele considerar la hipótesis de que los mensajes estaban, por defecto, destinados al enemigo, basándose en le evidencia de algunas balas griegas de plomo del período clásico y helenístico que portaban mensajes ofensivos. No obstante, al menos para las balas del siglo I a. C, coincidimos con Díaz Ariño en que sería difícil que el enemigo leyese los mensajes alojados en este tipo de artefactos. Parece más lógico pensar que los destinatarios de las inscripciones fuesen los propios soldados de la las legiones y que esto fuese un medio de propaganda de sus generales y mandos a fin de que se les conociese entre la tropa, no sólo a ellos, sino también sus reivindicaciones (Díaz Ariño, 2005, 231). En este contexto, no sería raro que los generales con una mayor necesidad de reivindicar su posición y pretensiones, emplearan con mayor asiduidad las glandes inscriptae, tal y como parece demostrar la mayor abundancia de ejemplares marcados por el bando sertoriano y por el pompeyano en el panorama de hallazgos hispanos. Volveremos sobre esta cuestión más adelante, a fin de trazar conclusiones.

Es precisamente en el panorama material del siglo I a. C, dónde hemos de poner la vista a la hora de trazar un contexto y establecer paralelos directos para el conjunto de piezas aquí estudiado. Los hallazgos de balas de plomo del siglo I a. C, son hoy por hoy, un fósil director principal para la reconstrucción de los movimientos tácticos y enfrentamientos de las guerras civiles de Roma en Hispania, tanto las sertorianas, como la de César contra los hijos de Pompeyo, especialmente aquellas que portan inscripción.

En 1990 el estudioso alemán Völling llevó a cabo un análisis detallado sobre los honderos y las balas de honda de los ejércitos romanos republicanos e imperiales cuyas tesis básicas siguen teniendo vigencia, su estudio destacaba la Península Ibérica como principal foco de hallazgos de época republicana (Völling, 1990, 51). Si nos ceñimos al mapa de dispersión de Völling (figura 5), veremos que la gran mayoría de proyectiles romanos de la Península Ibérica datan del siglo I a. C, además buena parte de los ejemplares se hallan en la Hispania Ulterior, con especial concentración en diversos enclaves de la Bética. No obstante, hemos de tener en cuenta publicaciones posteriores, que nos muestran una considerable ampliación de la distribución de hallazgos, especialmente en la $\mathrm{Ci}$ - 


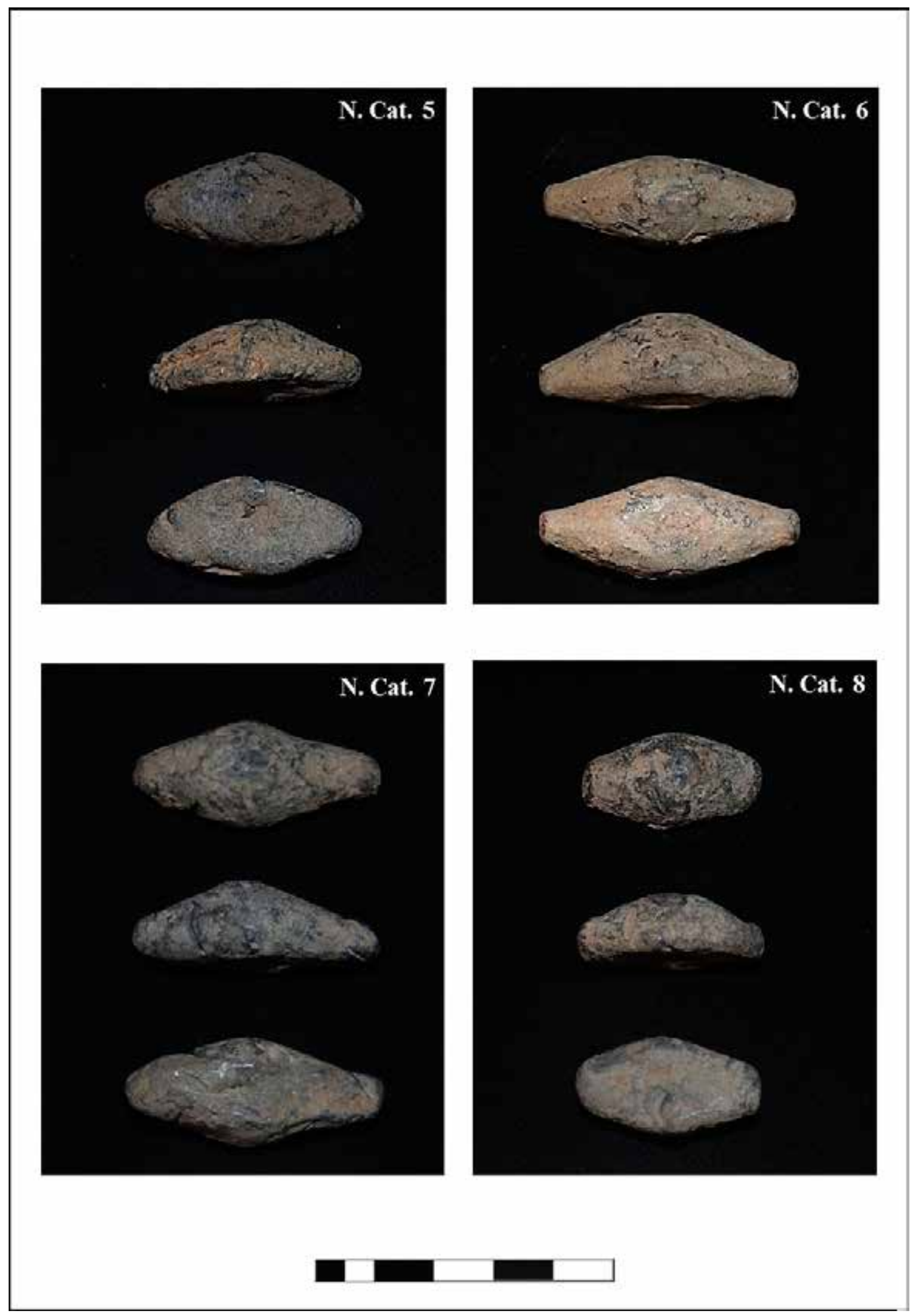

Figura 5. Lote de glandes del Cerro de Alvar Fañez (Huete). Fotografía de L. M. Saldaña Puentes y J. Moralejo Ordax. 
terior, con muchos más focos documentados con posterioridad a sus trabajos; de ellos iremos hablando para ponerlos en relación con nuestras piezas (Díaz Ariño, 2005, 32). Así pues, contamos con dos áreas de distribución de glandes de honda plúmbeas del siglo I a. C en la Península Ibérica: el área Bética, dentro de la Hispania Ulterior, y gran parte de la Hispania Citerior, con dos zonas de concentración: una en el área noroccidental de la provincia y la otra en determinados parajes de la zona suroccidental, en los territorios de lo que más tarde serían los límites entre la Baetica y la $L u$ sitania. El foco de concentración del área bética, viene caracterizado por la proximidad geográfica de los enclaves de hallazgo y está mayoritaria, aunque no exclusivamente, vinculado a las operaciones bélicas de cesarianos y pompeyanos en la zona; así lo demuestran las leyendas de muchas de las piezas que portan diversas inscripciones. Ya A. Schulten, se refirió al hallazgo de glandes plúmbeas en la ciudad cordobesa de Ategua, sitiada por César a inicios del año 45 a. C. (Shulten, 1940,128) ${ }^{8}$. Pina y Zanier llaman la atención sobre el hecho de que no se hayan documentado -al menos publicado- proyectiles de honda en los enclaves que Gneo Pompeyo asedió,

8 Además, el propio texto del Bellum Hispaniense confirma el empleo de glandes inscriptae como instrumento con el que transmitir mensajes. Caes. B.C. 13, 3: "idemque temporis glans missa est inscripta: quo die ad oppidum capiundum accederent, se scutum esse possiturum". antes de la llegada de César a Hispania, y sí en la provincia de Sevilla9. En efecto, se ha recuperado una cantidad considerable de balas en: las cercanías del Castillo de Alhonoz, el Cerro de las Balas, Los Argamasones, Cerro de las Camorras, El Gandul y en la antigua Vrso (Osuna) (Pina y Zanier, 2006, 41 y notas 20-24, para los textos alusivos a los generales y las legiones de las guerras civiles en las glandes; Quesada Sanz, 2008, 13-19 para las piezas de Osuna).Tomando como referencia las inscripciones de algunas piezas alusivas a determinadas legiones, se puede reconstruir parcialmente los movimientos de tropas en el transcurso del Bellum Hispaniense. Concretamente, los que portan la marca de la Legio XIII, proporcionan valiosa información sobre los movimientos pompeyanos en el contexto de la batalla de Munda (Pina y Zanier, 2006, 42. Para una hipótesis de reconstrucción de las vías de comunicación en el contexto del Bellum Hispaniense: Corzo Sánchez, 1973). En cualquier caso, estos lotes nos revelan un primer horizonte histórico a tener en cuenta en el que encuadrar los conjuntos de proyectiles de Hispania: el del enfrentamien-

9 Pina Polo, Zanier, 2006, 41. Actualmente estamos comenzando a estudiar las glandes acumuladas en el Museo de Montemayor, y recabando información sobre sus lugares de procedencia, probablemente asociados con el asedio de la antigua Ulia en el contexto de las guerras entre cesarianos y pompeyanos. Estos estudios y actividades se desarrollan en el marco del proyecto: HAR 2013-43683-p:"Resistencia y asimilación a la implantación romana en la Alta Andalucía"

Tabla. 2. Valores de recorridos y pesos medios de las glandes del lote del Cerro de las Balas. (Según datos extraídos de Pina y Zanier, 2012)

\begin{tabular}{|l|l|l|l|}
\hline \multirow{2}{*}{ Número total de ejemplares 48} & Grupo I & De 44,6 a 90,9 & 46,3 \\
& & & \\
\cline { 2 - 4 } \multirow{2}{*}{ Recorridos de peso por grupos (gr.) } & Grupo II & De 34,9 a 42 & 7,1 \\
\cline { 2 - 4 } & Grupo III & De 22,2 a 58,7 & 36,5 \\
\cline { 2 - 4 } & Grupo IV & De 23,8 a 103,2 & 76,4 \\
\hline Recorrido total de pesos (gr.) & De 26,8 a 103,2 & 79,4 \\
\hline Peso medio del conjunto completo (gr.) & 52,6 & \\
\hline
\end{tabular}


Tabla. 3. Valores de pesos medios de los proyectiles plúmbeos del Cerro de la Alegría (Monzón) y Sanitja.

(Según los datos de Contreras et alii, 2006-2007)

Número total de ejemplares

Cerro de la Alegría (Monzón)

63 (plúmbeas)

Sanitja

Pesos medios (gr.) por tipos de Völling.

\begin{tabular}{|l|l|l|l|}
\hline Völling 1a & 35,5 & Völling 1a & 56,5 \\
\hline Völling 1c & 43 & Völling 1b & 86,3 \\
\hline Völling 2a & 40 & Völling 1c & 79,5 \\
\hline Völling 2b & 50 & Völling 2a & 65 \\
\hline & Völling 2b & 64,1 \\
\cline { 3 - 4 } & & Variante local & 53,3 \\
\hline
\end{tabular}

to entre César y Pompeyo. Cabe señalar, asimismo, que nos proporcionan un repertorio tipológico considerable para establecer paralelos.

GLANDES DEL ENFRENTAMIENTO ENTRE CÉSAR Y POMPEYO.

De este primer foco cabe reseñar el hallazgo de glandes inscriptae de la Mesa del Gandul, en el municipio sevillano de Alcalá de Guadaira. En esta localidad se han localizado abundantes balas de plomo con inscripción, algunas con las leyendas: l(egio) XIII/ $Q(\dot{i})$ y $A$ (i)y otras anepígrafas con iconografía, en este caso, portan el motivo del fulmen (Villaronga, 1983, 62; 72; Casariego et alii, 1987, 20- 21; Díaz Ariño, 2005, 222). Los primeros editores de estas piezas las dataron en la II Guerra Púnica, y la adscribieron a la Legio XIII, que llegó a Hispania procedente de Sicilia poco después del año 210 a. C, para reforzar los contingentes romanos (Villaronga, 1983, 72; Casariego et alii, 1987, 21). Las balas del Gandul aparecieron, además, junto a material numismático cartaginés que parecía apoyar la datación a fines del siglo III a. C, lo que convertía a este conjunto en el más antiguo de glandes inscriptae latinas de la Península Ibérica. Sin embargo, como bien señala Díaz Ariño, se trata de material proveniente de rebuscas clandes- tinas y carente de contexto arqueológico fechable, como la totalidad de las piezas recuperadas en suelo hispano. Por tanto, la asociación al numerario cartaginés, así como el propio origen de las piezas resulta muy discutible (Díaz Ariño, 2005, 222) Creemos más acertada la hipótesis de datación de Díaz Ariño para el lote del Gandul en el siglo I a. C y su contextualización en la campaña de Ilerda en el año 49 a. C. Por tanto, consideraremos aquí este conjunto como uno más de los documentados para las guerras civiles romanas.

\section{Glandes de la Hispania Ulterior.}

Del territorio de la Bética no podemos dejar de señalar un conjunto de una decena de balas localizado en Encinasola (Huelva) de las que dos piezas portan inscripción alusiva a las guerras sertorianas. La lectura de los textos sitúa el lote entre los años 80 y 77 a. C, aunque Díaz Ariño fecha las piezas en el año 76 a. C, tras la retirada de Sertorio a la Citeri-

$10 \mathrm{El}$ autor esgrime otros argumentos en contra de la datación de este conjunto a fines del III a. C. como la dudosa presencia de la Legio XIII en Hispania en las fechas mencionadas. Así, también, confirma las balas de Henna de Lucio Pisón (CIL I ${ }^{2} 847$ ), fechadas con certeza en el último tercio del siglo II a. C, como las más antiguas documentadas con inscripción latina. 


\begin{tabular}{|c|c|c|c|c|c|c|c|c|c|c|c|}
\hline \multirow{2}{*}{$\begin{array}{l}\text { Cerro de las } \\
\text { balas } \\
52,6\end{array}$} & \multicolumn{4}{|c|}{$\begin{array}{l}\text { Cerro de la Alegría } \\
\text { (Por tipos Völling) }\end{array}$} & \multicolumn{6}{|c|}{$\begin{array}{l}\text { Sanitja } \\
\text { (Por tipos Völling) }\end{array}$} & \multirow{2}{*}{$\begin{array}{l}\text { Huete } \\
45\end{array}$} \\
\hline & 35,5 & 43 & 40 & 50 & 56,5 & 86,3 & 79,5 & 65 & 64,1 & 53,3 & \\
\hline \multicolumn{9}{|c|}{ Pesos medios del conjunto del lote } & & & \\
\hline \multicolumn{3}{|l|}{43,7} & \multicolumn{6}{|c|}{65,015} & & & \\
\hline
\end{tabular}

or (Díaz Ariño, 2005, 225). No lejos de Encinasola, en la localidad de Azuaga, (Badajoz) apareció el lote cuantitativamente mayor documentado hasta la fecha. En este lugar se exhumaron 2000 proyectiles de plomo, con un peso total de $100 \mathrm{~kg}$. Todos ellos aparecieron agrupados, como si hubiesen sido ordenados y almacenados en algún contenedor. En la prospección arqueológica del enclave se hallaron también abundantes escorias de plomo que parecen indicar, según Domergue, que la munición fue fabricada en el mismo lugar donde apareció almacenada y que, probablemente, no llegó a ser utilizada (Domergue, 1970). De todos los ejemplares localizados, tan sólo unos cuantos tenían inscripción latina, la misma en dos variantes: $Q$. $M E$ y Q. MET. La lectura y desarrollo de los textos no presenta problemas especiales: se puede asumir la lectura: Q(uinctus) Me(tellus), e identificar este nombre con el del cónsul Quinctus Caecilius $M e$ tellus, general del bando senatorial en las guerras entre Sertorio y el Senado en la zona de Lusitania (Broughton 1951) ${ }^{11}$. Los ejemplares han sido datados entre los años 79 y 76 a. C. La forma en la que aparece esta inscripción en todas las glandes inscriptae alusivas a este cónsul romano, será, como veremos más adelante, un criterio a tener en cuenta para la contextualización del conjunto de Huete. En 2006, Pina y Zanier daban a conocer un conjunto de 49 glandes de plomo pertenecientes a un coleccionista privado. Las piezas provienen su-

11 Las operaciones de Cecilio Metelo en la Lusitania están bien documentadas en los textos, por lo que podemos situar su paso por esta zona en el año 77 a. C, en los primeros tiempos del conflicto. Las glandes de Azuaga habrían sido fabricadas, almacenadas y posteriormente abandonadas sin usar por las tropas de Caecilius Metellus. puestamente, según los autores, del llamado Cerro de las Balas o Cerro de la Atalaya, en la provincia de Sevilla, uno de los escenarios propuestos para la localización de la batalla de Munda, en el año 45 a. C. De las 49 piezas, 46 portan inscripción y han sido divididas en cuatro grupos en razón de su inscripción: grupo 1: CN MAG; grupo 2 LXIII; grupo $3 \mathrm{~A}$; grupo $4 \mathrm{DD}$ (Pina y Zanier, 2006). Las leyendas han sido interpretadas dela siguiente manera: Cn(aeus) Mag(nus); L(egio) XIII; A(z) y $D$ (ecreto) D(ecurionum) (Nuñez Pariente de León, Quesada Sanz, 2000; Pina y Zanier, 2006) ${ }^{12}$. La tipología de las glandes hispanas es, por lo general, bastante uniforme, no obstante, y prescindiendo ahora del elemento epigráfico, existen similitudes tipológicas relevantes entre el conjunto aquí estudiado y el lote del Cerro de las Balas, que conviene no perder de vista. En el catálogo de glandes inscriptae de Pina y Zanier, concretamente en los tres primeros grupos, nos topamos con piezas fabricadas en molde univalvo, muchas de ellas adscribibles al tipo 1c de Völling, y, presentan la inscripción en la parte superior de la pieza, y la parte de su base, aparece aplanada. Se trata de un rasgo muy poco común, que, sin embargo comparten otros ejemplares con inscripción hallados fuera de la Península Ibérica, según testimonio de los autores (Pina y Zanier, 2006, 31). Este rasgo es identificable en algunos de los ejemplares de nuestro propio catálogo,

12 El Cerro de las Balas se encuentra en uno de los caminos viejos entre Écija y Osuna ("Camino del cortijo del Villar") dónde se produciría algún episodio de la Batalla de Munda. De este yacimiento proceden cuarenta y nueve glandes comprados en un mercado de antigüedades de Sevilla en el año 2005. 
pero todos ellos anepígrafos ${ }^{13}$. En el grupo cuatro, por el contrario, predominan los tipos generales, con especial presencia del modelo $2 \mathrm{~b}$ almendrado, por lo demás, la forma más común documentada en Hispania (Pina y Zanier, 2006, 35, fig. 49). Descendiendo más al detalle, existen dos similitudes muy concretas que no quisiéramos dejar de señalar: el ejemplar n. 35 de Pina y Zanier, es idéntico a nuestro ejemplar n. 9 (Pina y Zanier, 2006, 35, fig. 4, n. 35). Ambos modelos son casos arquetípicos del tipo llamado "bicónico" fabricado en molde bivalvo y a menudo con rebabas en su parte lateral. De la misma manera, hallamos paralelos directos en los conjuntos de Osuna, que se caracterizan por su morfología bicónica; podemos destacar las formas del grupo A de las glandes inscriptae del estudio de Le Roux, como modelos idénticos morfológicamente (Le Roux, 1997, 68-70; Quesada Sanz, 2008, 16, fig. 10). Ahora bien, tanto el proyectil del Cerro de las balas, como los de Osuna, arrojan pesos significativamente mayores que el de Huete: $\mathbf{5 2}$ gr. y 80 gr. respectivamente, frente a los escasos 40 gr. de la pieza de Huete. El segundo aspecto reseñable tiene que ver el marcado rehundimiento en la parte central de la base de algunas piezas. Lo cierto es que los ejemplares n. 17 y 18 del catálogo del Cerro de las Balas (Pina y Zanier, 2006, 33, fig. 2. n. $17 ; 18)$, presentan la misma característica, además, se pueden adscribir al mismo horizonte tipológico, el tipo 1c de Völling. Pina y Zanier interpretan este rasgo como fruto probable de la fabricación apresurada de la munición en los momentos inmediatamente previos a un conflicto armado (Pina y Zanier, 2006, 31). De los 49 ejemplares con inscripción no hallamos ningún ejemplar con la misma inscripción que la única glans inscripta conservada en el lote de Huete que aquí presentamos.

En lo referente a los pesos, el conjunto del Cerro de las Balas nos da indicios de la gran variabilidad de pesajes presente en lotes cuantiosos y nos muestra una media sensiblemente más alta que la del conjunto aquí estudiado, pero significativamente baja en correspondencia con otros conjuntos del siglo I a. C. (Tablas n. 2 y 4 ).

Las balas aparecidas en la Hispania Ulterior, pertenecen, como hemos visto, mayoritariamente a las guerras entre César y los hijos de Pompeyo,

13 catálogo tipológico, n. 2, n.4, n.5, n. 8. Siendo, no obstante, más acusado el rehundimiento de las piezas de Huete. aunque algunos de los conjuntos más destacados datan del período Sertoriano y tienen su contexto en las operaciones llevadas a cabo en el norte de la Bética antes de la retirada de Sertorio a la Citerior. Por el contrario, hasta hace poco se había venido afirmando que ninguno de los lotes aparecidos en la Citerior, pertenecían al período de las guerras civiles del 48 al 45 a. C (Díaz Ariño, 2005 225). Como veremos, este lote de Huete, junto a otros hallazgos publicados entre los años 2006 y 2013, desmienten esta afirmación, cuestión que trataremos más adelante, tras repasar el panorama de la Citerior.

\section{Glandes de la Hispania Citerior.}

Procedentes de diversos lugares repartidos por la Hispania Citerior, contamos con otros grupos de proyectiles y hallazgos de un solo ejemplar de época tardo-republicana que debemos considerar para establecer una contextualización adecuada. Se han documentado balas con inscripción latina en gran parte de la zona interior de la antigua provincia romana: Navarra, Huesca, Soria, Zaragoza y Guadalajara. Todos los ejemplares de estos lugares portan leyendas adscribibles al bando sertoriano. En la provincia de Zaragoza, contamos con un ejemplar, otros tres similares en Fitero, en el límite meridional de Navarra, y cuatro más en Aranguren, también en Navarra. En el área de la actual provincia de Guadalajara, concretamente en la Muela de Alarilla y la Muela de Taracena, contamos con cuatro balas inscritas (Díaz Ariño, 2005), dos por cada lugar. Todos los ejemplares mencionados, portan diferentes variantes de la inscripción: Q. SERTORI. PROCOS: Q(uinctus) S(ertorius) Proco(n) $s(u l)$ en una de sus caras, acompañada, en la otra, por diversos mensajes de cariz ideológico-propagandístico: FIDES, VERITAS, PIETAS, IVS, y diversos motivos iconográficos que refuerzan dichos mensajes (Stylow, 2005, 252-253, nota 27) ${ }^{14}$. Todos ellos parecen datarse entre los años 77 y 72 a. C y su tipología, se inserta, de nuevo, en los dos

14 Motivos como las fasces, según Stylow, se pueden asociar a la legitimidad de Sertorio frente a sus enemigos; la palma a su victoria o el timón a la fortuna. Todo ello iría directamente vinculado con la leyenda que proclama a Sertorio como procónsul legítimo y los eslóganes como IUS o PIETAS, entre otros, conformando una "campaña publicitaria” que eligió las glandes como soporte de su mensaje. Díaz Ariño, 2005, pp. 233-235 (Anexo) para un estudio individual de cada pieza. Un estudio completo de la cuestión de la PIETAS en el contexto sertoriano en Beltrán LLoris 1990. 
primeros tipos de Völling, con especial abundancia de los modelos $2 \mathrm{a}$ y $2 \mathrm{~b}$ entre aquellos ejemplares que portan inscripción; lo que viene a coincidir, en términos generales, con las características de la glans inscripta de Huete. Atendiendo a las leyendas de las piezas con inscripción, podemos asociar este foco de concentración de balas al período central del conflicto entre Sertorio y el Senado, una vez que el general rebelde estableció sus bases en la Provincia Citerior (Díaz Ariño, 2005, 226 con bibliografía).

En el año 2006 aparecía un trabajo monográfico que daba a conocer y analizaba 79 proyectiles procedentes de tres yacimientos aragoneses depositados en el Centro de Estudios Históricos de Monzón (CEHIMO), en la provincia de Huesca. La mayor parte proviene del Cerro de la Alegría, concretamente sesenta y nueve, otros seis del enclave de Lo Pingato y los cuatro restantes de Ripoll-Saso, todos ellos parajes con materiales arqueológicos documentados pero ninguno de ellos excavado. El estudio de estas piezas llevado a cabo por F. Contreras y otros (Contreras et alii, 2006-2007, 1-47, 40 ), sitúa todas las glandes en los tipos I y II de Völling, sin embargo, lamentamos la ausencia de documentación gráfica, especialmente dibujos, que nos permita una comparación tipológica precisa con las piezas de Huete; una comparación que habría resultado, sin duda, enriquecedora. Sí conocemos la información relativa a los porcentajes tipológicos de cada grupo de Völling, así como los pesos individuales y medios de los conjuntos (Tabla n.3). En este caso, nos interesan los dos lotes grandes: el de Sanitja y el del Cerro de la Alegría. Los autores del estudio de ambos conjuntos han tenido la posibilidad de tomar muestras en dos lotes abundantes en número y diversidad tipológica de glandes.

Con todo, lo que aparentemente vincula al conjunto de glandes de la Citerior depositado en el CEHIMO con los once ejemplares que aquí analizamos, y a su vez con otro ejemplar del numeroso conjunto de Sanitja (Menorca), que no ha sido publicado, es la existencia de una glans inscripta en los tres lotes con la misma leyenda: $S C A E$. Todos ellos se deben poner en relación, a su vez, con los hallazgos de Picamoixons y Prades, en Tarragona, cuya reciente publicación nos dirige hacia una posible contextualización del conjunto de Huete.
LA INSCRIPCIÓN SCAE EN LAS GLANDES PLÚMBEAS DE LA HISPANIA CITERIOR

En su amplio trabajo sobre las glandes inscriptae de Hispania, B. Díaz Ariño asevera repetidamente que todas las piezas con inscripción latina documentadas en Hispania, datan del período de las Guerras Civiles de Roma en el transcurso del siglo I a. C. La glans inscripta del conjunto de Huete porta la abreviatura $S C A E$ en una de sus caras, sin ningún tipo de mensaje en el reverso, ni símbolo iconográfico que lo acompañe. Contamos con varios paralelos directos para nuestra pieza, provenientes del Cerro de la Alegría de Monzón en Huesca), (figura 8), Sanitja en Menorca (figura 9), Picamoixons (Tarragona) y Prades (Tarragona). De los dos primeros lugares citados, tan sólo encontramos, como en el caso de Huete, una bala, con esta inscripción, mientras que, en los hallazgos tarraconenses, hay una enorme cantidad de ellas que la llevan (López Vilar, 2013) ${ }^{15}$.

Del área portuaria del antiguo fortín romano de Sanitja (Menorca), procede un lote de 80 glandes recuperadas del interior de diversas estancias del yacimiento. De dicho conjunto sólo se ha publicado una pieza, que porta la inscripción latina $S C A E$ (Contreras et alii, 2006-2007, 15; De Nicolás, 1983, p. 87, fig. 46; Domínguez, Maestro, 2002, 87, fig. $46)^{16}$. De Nicolás, que publicó la pieza, y posteriormente el equipo de excavación del yacimiento, han desarrollado la inscripción de la siguiente manera: $Q$ (uintus) CAE(cilius) considerando que la primera letra ha de leerse separada del resto y, que no se trata de una $S$ sino de una $Q$ "retrógrada" de panza abierta. La inscripción es prácticamente idéntica, desde el punto de vista paleográfico, en los ejemplares de Monzón, Sanitja, Tarragona y Huete. Tan sólo podríamos poner una pequeña excepción en una de las dos variantes de las piezas de Picamoix-

15 El trabajo de López Villar, aparecido recientemente, esclarece, a nuestro juicio, de la manera más probable, la vía de interpretación más adecuada para los proyectiles de honda con la inscripción $S C A E$.

$16 \mathrm{El}$ conjunto de Sanitja permanece inédito. De las 80 glandes recuperadas, 22 aparecieron, en una estancia, amontonados. El contexto de hallazgo de estos 22, así como el del resto, todos hallados en estancias del recinto militar, ha llevado a los excavadores a aventurar que la presencia de estos proyectiles en el yacimiento menorquín no responde al suceso de un combate en dicho lugar, sino que, más bien, se almacenaban como munición quizá para la instrucción de tropas acantonadas en el fortín. 


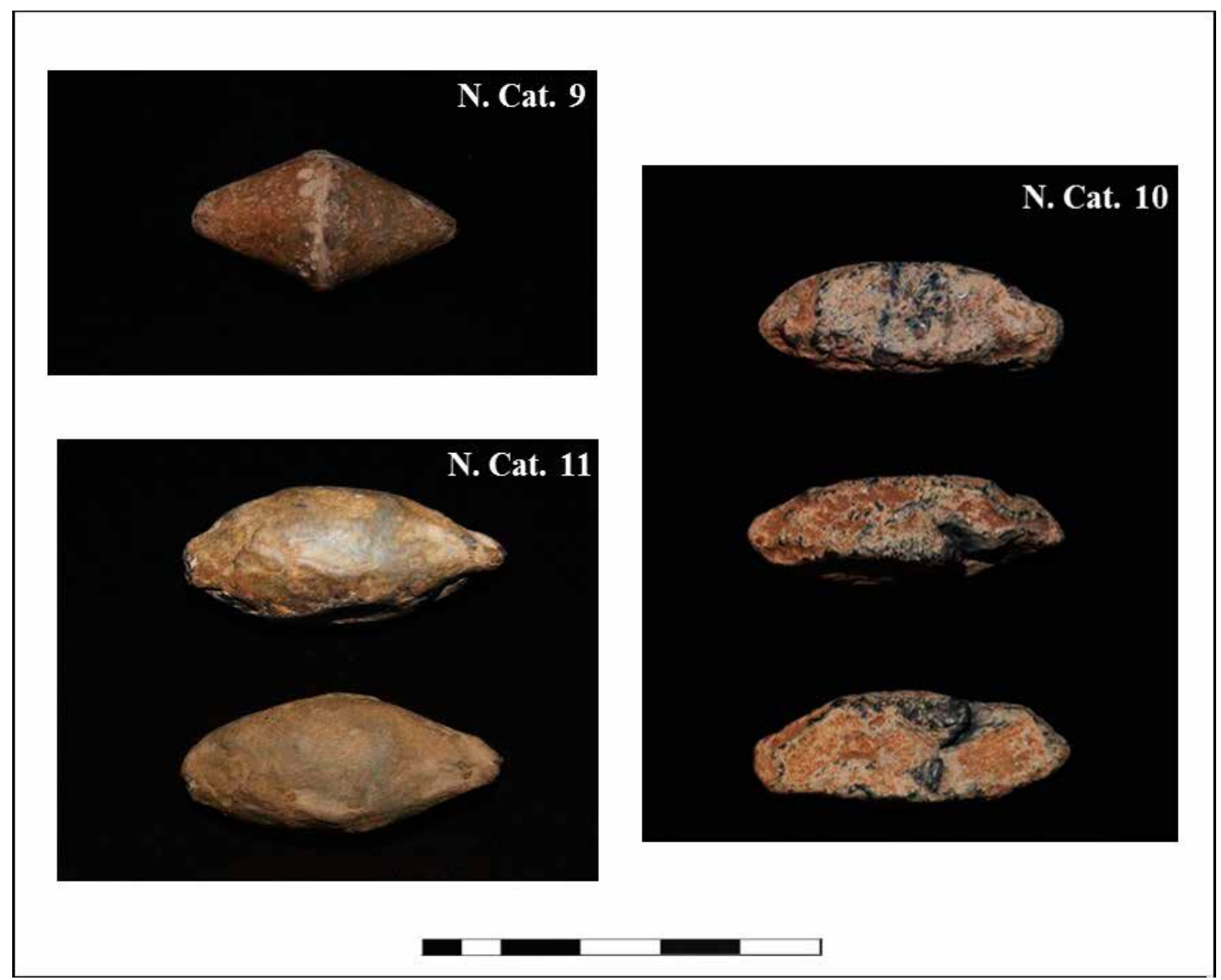

Figura 6. Lote de glandes del Cerro de Alvar Fañez (Huete). Fotografía de L. M. Saldaña Puentes y J. Moralejo Ordax.

ons, que presenta las letras ligeramente más separadas. Ello les ha llevado a vincular directamente esta pieza con el cónsul Quinto Cecilio Metelo y, consecuentemente, a datarla en el período de las guerras sertorianas (Contreras et alii, 2006, 242). Estos investigadores han interpretado en el mismo sentido el proyectil hallado en Monzón (figura 8), con idéntica inscripción SCAE (Contreras et alii, 2006, 242-243, nota 53) ${ }^{17}$. Sin embargo, tan sólo conocemos tres balas con inscripción alusiva a Cecilio Metelo, todas ellas pertenecientes al ya

17 Estos autores apoyan la datación en época sertoriana de las piezas de Sanitja y Monzón resultante de su lectura del texto, con otros datos como: la presencia documentada por las fuentes clásicas de cuerpos de honderos en las fuerzas de Sertorio y en las de Cecilio Metelo, cuyo reclutamiento relacionan con las redes clientelares de ambos con los pueblos indígenas de Hispania. Además, sitúan tanto Monzón, en el ámbito territorial de Osca, como Sanitja, como escenarios de operaciones tácticas y logísticas llevadas a cabo por ambos generales romanos en el transcurso del conflicto. mencionado conjunto de Azuaga. Las piezas podrían datarse entre los años 79 y 76 a. C, cuando los ejércitos senatoriales de la Ulterior estuvieron bajo el mando del cónsul. Las leyendas de estas tres balas, rezan: Q(uinctus) $M e\left(\right.$ tellus) $\left(\mathrm{CIL} \mathrm{II}^{2}\right.$ 17 885c); Q(uinctus) Met(ellus) (CIL II ${ }^{2} 7$ 885b) y $Q$ (uinctus) $M$ (etellus) (CIL $\mathrm{II}^{2} / 7$ 885a; Díaz Ariño, 2005, 233 (anexo) n. 1; 2; 3). En ningún caso aparece el nomen Caecilius consignado en las piezas. Aparte de las dificultades paleográficas ya expuestas para leer $Q$ (uinctus) Cae(cilius) en las glandes de Monzón y Sanitja (también en la de Huete), este hecho dificulta, aún más, la hipótesis de lectura propuesta por Contreras et alii.

Recientemente, se han dado a conocer en Tarragona, dos hallazgos de glandes plúmbeas -a los que ya nos hemos referido- que, tanto por la cantidad de ejemplares analizados, como por el contenido de las inscripciones que incorporan, son de gran interés para nosotros (López Vilar, 2013a; López Vi- 


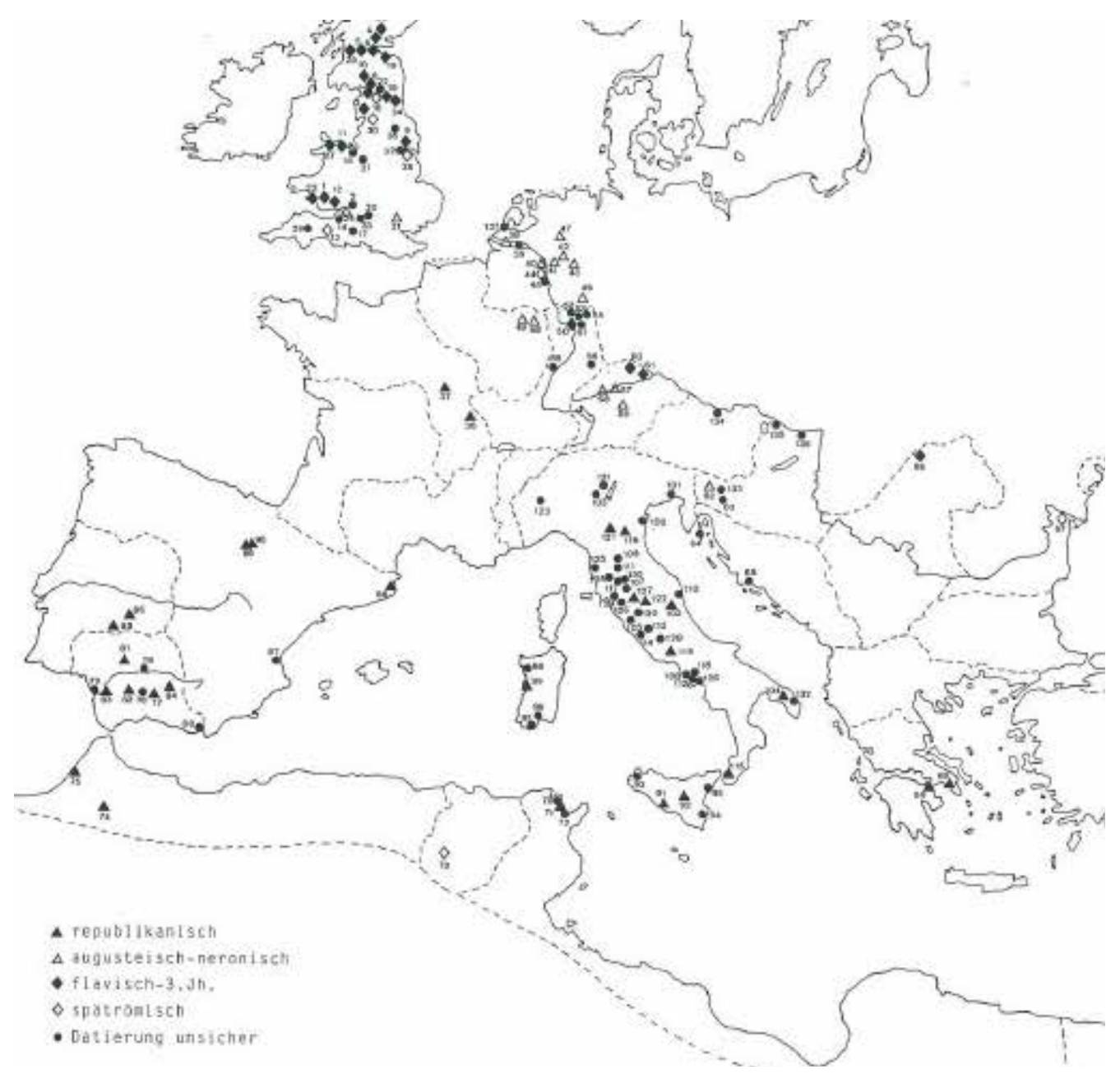

Figura 7. Mapa de distribución de hallazgos de glandes plúmbeas. Según Völling, 1990, p. 51, fig. 30.

lar, 2013b) (Figs. 10 y 11). El primero es un conjunto de 82 proyectiles procedentes de la localidad tarraconense de Picamoixons (López Vilar, 2013a, 176)18. Todas las piezas, atribuibles al tipo $2 \mathrm{~b}$ de Völling al igual que la pieza inscrita de Huete (figura 12), portan la inscripción $S C A E$, en dos variantes: una con las letras más grandes y separadas, y otra con las letras más reducidas y dispuestas a menor distancia unas de otras ${ }^{19}$. El proceso de fabricación de

18 Las glandes aparecieron esparcidas por las labores agrícolas en un radio de $50 \mathrm{~m}$, en un terreno rocoso sin apenas potencia estratigráfica, por lo que el autor supone que hubieron de estar algo más concentradas en su deposición original además de haber sido empleadas en una escaramuza.

19 López Vilar interpreta el yacimiento de Picamoixons como un punto de control o de acampada instalado por poco tiempo en algún momento de las operaciones bélicas estos proyectiles es exactamente el mismo que el que se observa en nuestro ejemplar n. 1, elaborado con molde bivalvo, y la inscripción ha sido realizada en ambos casos en el momento de la fabricación de la pieza. En cuanto al texto, López Vilar presenta una lectura bien distinta que la de Contreras y a nuestro juicio más probable. En primer lugar, ve dos problemas esenciales en la lectura Q(uinctus) $C A E$ (cilius): el de la letra inicial y su identificación

en territorio tarraconense por las tropas cesarianas, de esta manera explica la ausencia de restos cerámicos. Asimismo, afirma que un lote tan numeroso en proyectiles sólo se explica como producto de un abandono premeditado como resultado de una huida precipitada. Esta hipótesis sigue la línea argumental de la interpretación de otros grandes conjuntos de glandes documentados en la Península, como el de Azuaga. Cf. López Vilar, 2013ª $176,51$. 
como una $Q$, así como el considerar la inicial de la inscripción como una letra independiente del resto. La inicial de las glandes de Sanitja y Monzón, es claramente una $S$ y convertirla en una $Q$ resulta muy forzado. De la misma manera, la primera letra de la pieza de Huete, a pesar de estar dañada parcialmente por una muesca, es, igualmente una $S$.

El segundo hallazgo, dado a conocer por López Vilar en el mismo trabajo, se sitúa en la villa de Prades, donde se hallaron dos balas de plomo con inscripción. Una de ellas con la leyenda $S C A E$ es del mismo tipo que las descritas anteriormente, aunque presenta un notable desgaste que ha afectado a la inscripción. El ejemplar mide 4,3x1,5 cm y presenta un peso de $60,9 \mathrm{~g}$, ligeramente más grande y pesado que la pieza de Huete $(4,1 \times 1,9 \mathrm{~cm}$ y 56 g). El segundo proyectil de Prades es morfológicamente diverso y se encuadra, según el autor, en el tipo 1 de Völling; ofrece unas medidas de 4,3x1,5 $\mathrm{cm}$ y pesa 61,6 g. Presenta inscripciones en sendas caras, enmarcadas por sendas cartelas de ángulos redondeados (López Vilar, 2013 ${ }^{\mathrm{a}}, 178$ y 2103b, 434-435), con el numeral XII precedido de dos símbolos iconográficos distintos y de muy dudosa interpretación (López Vilar, 2013 $\left.{ }^{\mathrm{a}}, 178\right)^{20}$. El numeral XII se puede vincular, sin grandes problemas, a la legio XII cesariana que participó en el Bellum Hispaniense.

La inscripción de las glandes mencionadas es idéntica a la de Huete y ha de leerse, a nuestro juicio, como una sola palabra: $S C A E$. López Vilar, que ha rastreado esta marca en proyectiles plúmbeos fuera de la Península Ibérica, ha encontrado un ejemplar análogo en Perugia (Perusia) que porta la leyenda (figura 13): Le(gio) XII Scaeva / prim(us) pil(us) (Zagenmeister, 1885; Benedetti, 2013) ${ }^{21}$. Zagenmeister fechó la bala en los años de la guerra de Perusia, entre las tropas de Lucio Antonio y Fulvia y las de Octaviano (41-40 a. C) y López Vilar ha interpretado Scaeva como el antropónimo de un primipilo de la legio XII (López

20 Uno de los símbolos que acompaña a la inscripción con el numeral XII está visiblemente afectado por el desgaste de la pieza, el otro podría ser interpretado, según López Vilar, de diversas maneras: un ojo de Horus, o, quizás una cabeza de pájaro. Para la primera no parece haber paralelos y la segunda interpretación es muy dudosa.

21 El trabajo de Benedetti revisa y pone al día el conocido estudio de Zagenmeister sobre las 80 balas de honda halladas en la ciudad de Perugia pertenecientes al Bellum Perusinum.

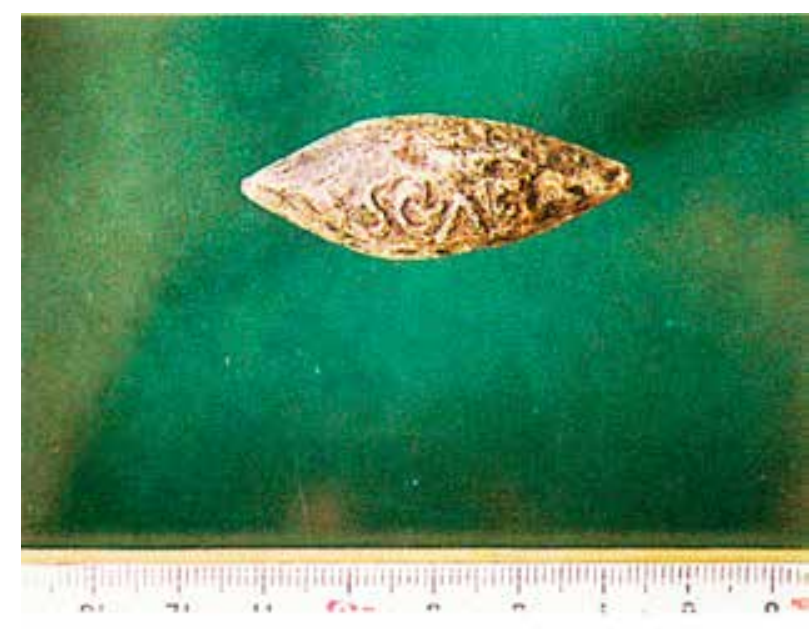

Figura 8. Glans inscripta con leyenda SCAE proveniente del Cerro de la Alegría (Monzón). Según Domínguez Arranz-Maestro Zaldivar, 2002, p. 87, fig. 46.
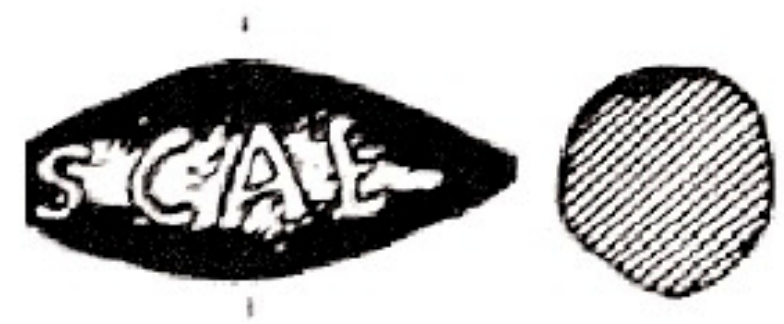

Figura 9. Glans inscripta con leyenda SCAE proveniente de Sanitja (Menorca). Según De Nicolás, 1983, p. 87, fig. 46.

Vilar, 2013a, 179; Zagenmeister, 1885, n.79). Como apunta López Vilar, la datación de la pieza italiana es tan sólo 8 o 9 años posterior al paso de la Legio XII por Hispania y de modo análogo podría reflejar el nomen de un centurión llamado Marcus Cassius Scaeva que se distinguió en combate a las órdenes de César y que aparece mencionado en el relato del Bellum Hispaniense. Scaeva combatió bajo los estandartes cesarianos en la batalla de Dyrrachium, en la que se distinguió por su valor, $y$, a juzgar por la mención, hubo de ser un soldado bastante conocido en el ambiente militar de la época (Bell. Hisp. 1, 53; López Vilar, 2013b, 439440 , nota 34$)^{22}$. El propio López Vilar sugiere otras

22 "Et cum laboris sui periculique testimonium afferre vellent, milia sagittarum circiter $X X X$ in castellum coniecta Caesari renumeraverunt, scutoque 


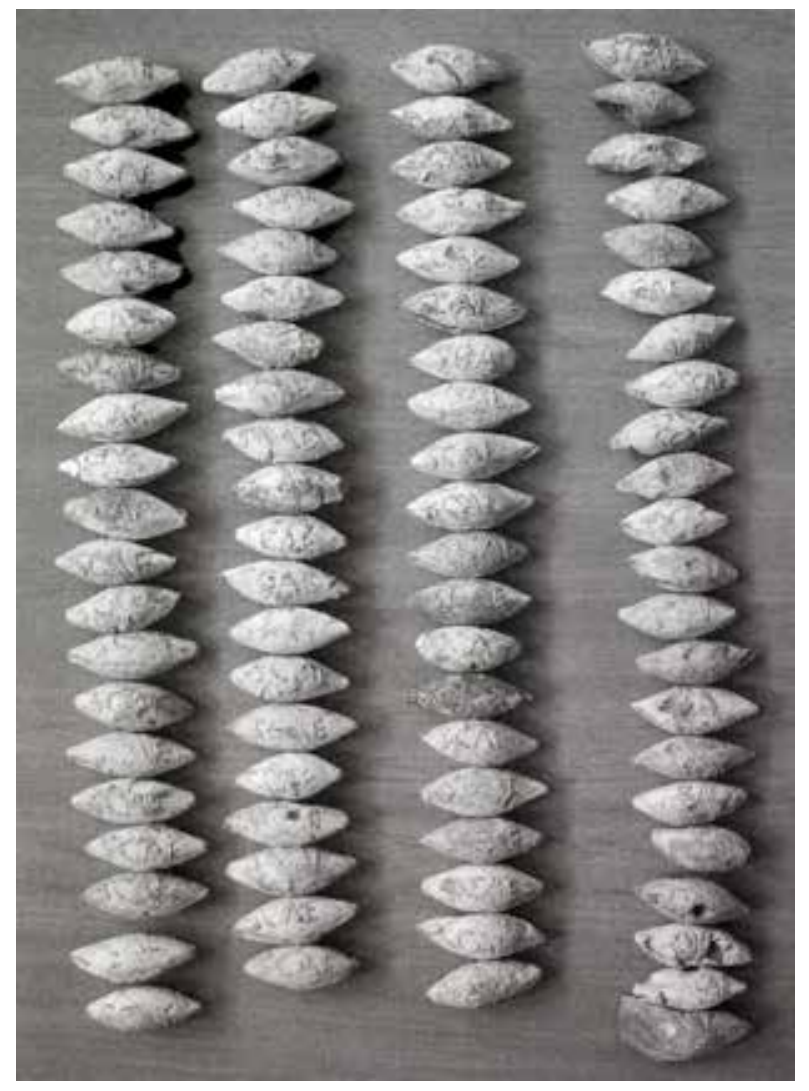

Figura 10. Glandes inscriptae con leyenda SCAE provenientes de Picamoixons (Tarragona). Según López Vilar, $2013^{\mathrm{a}}$, p. 176, fig. 2. posibilidades documentando una serie de soldados y oficiales con el cognomen Scaeva, además de una serie de unidades militares que portan el mismo término, sin embargo, todos estos testimonios se fechan a lo largo del siglo I d. C (López Vilar, 2013b, 442-443; Coleman, 1996) ${ }^{23}$. Uno de estos testimonios resulta relevante por su datación: una inscripción de Minturne datada hacia el año 30 a. C, en la que figura un ala Scaevae, una unidad auxiliar, que ha llevado a algunos investigadores a suponer que fue creada en los años de la Guerra de las Galias y nombrada así en honor del primipilo citado (Keppie, 1998, 151; Bowmann et alii, 1996, 381, a través de López Vilar 2013a, 180). De aceptar

ad eum relato Scaevae centurionis inventa sunt in eo foramina $C X X$. Quem Caesar, ut erat de se meritus et de re publica, donatum milibus CC collaudatumque $a b$ octavis ordinibus ad primipilum se traducere pronuntiavit (eius enim opera castellum magna ex parte conservatum esse constabat) cohortemque postea duplici stipendio, frumento, veste, cibariis militaribusque donis amplissime donavit”. La costumbre de distinguir a soldados y oficiales es común en el relato de César.

23 Parece que significado etimológico de Scaeva, es el de “zurdo”. Descartamos aquí el uso del término Scaeva para designar a gladiadores que esgrimían el arma principal con la mano izquierda, documentado en varias inscripciones y en un grafito de Pompeya. Para un desarrollo de la cuestión, cf. Coleman, 1996.

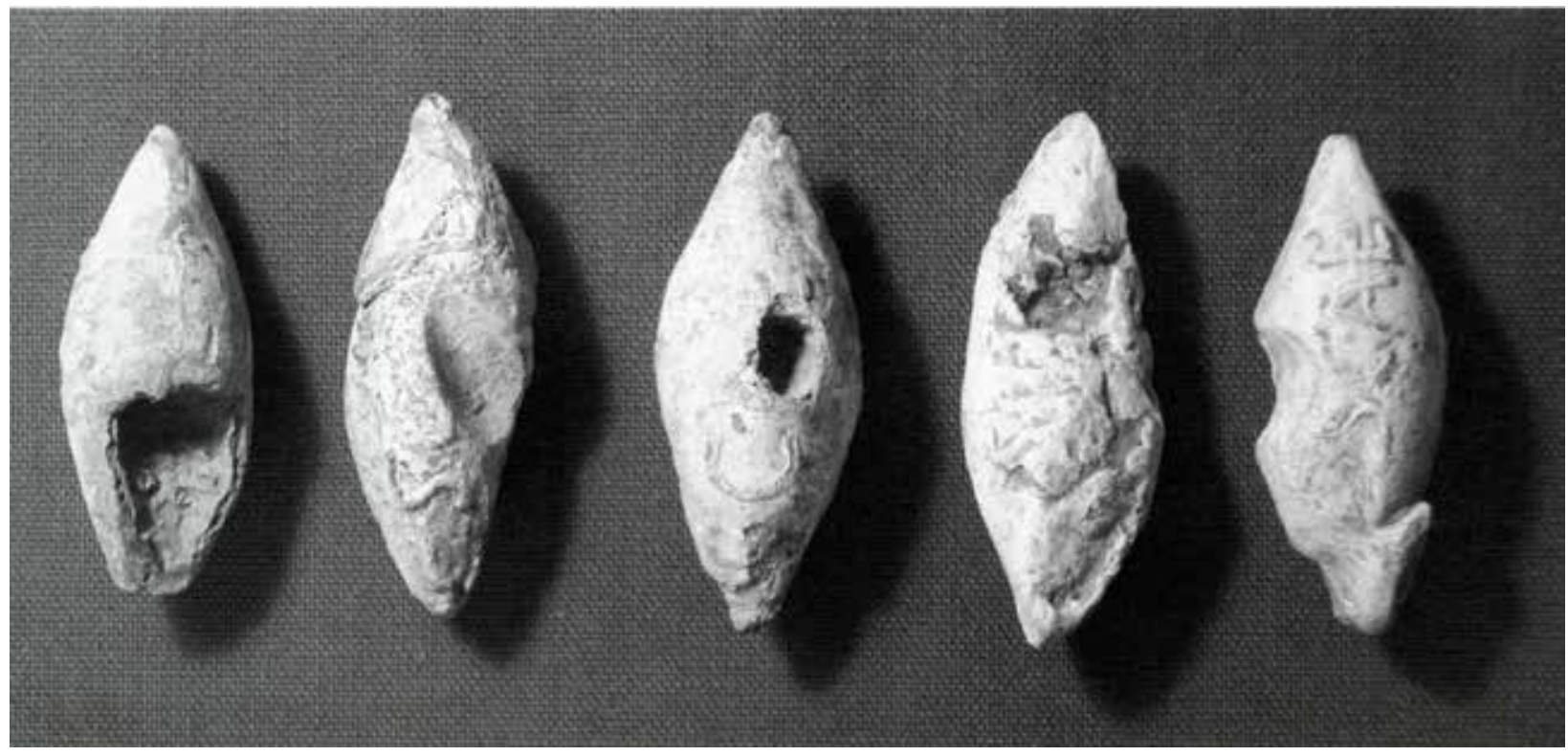

Figura 11. Detalle de glandes inscriptae con leyenda SCAE provenientes de Picamoixons (Tarragona). Según López Vilar, 2013b, p. 453, fig. 5c. 


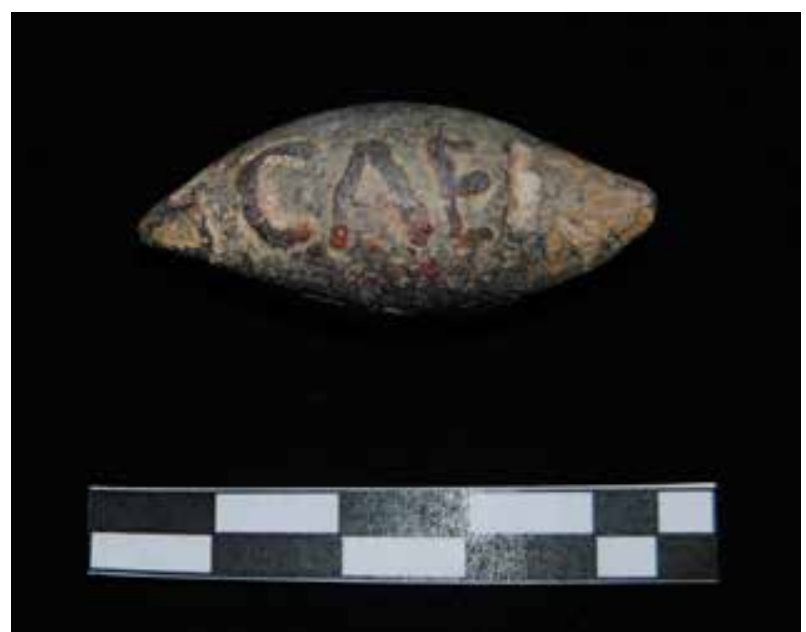

Figura 12. Glans inscripta con leyenda SCAE proveniente del Cerro de Alvar Fáñez (Huete, Cuenca). Fotografía de los autores.

la primera hipótesis, estaríamos ante un $\operatorname{Scae}(v a)$, suboficial de la duodécima legión que combatió en el Bellum Hispaniense (López Vilar, 2103b, 440$441)^{24}$, y las glandes de Picamoixons y de Prades, así como los paralelos de Sanitja y Monzón y la n. 1 de de Huete, hallarían, pues, contexto durante las operaciones militares desarrolladas antes y después de la batalla de Ilerda en el 49 a. C.

Una tercera interpretación propuesta por López Vilar, y antes por B. Díaz Ariño (2008, 256), vincula la leyenda $S C A E$ con P. Mucius Scaevola, un personaje de la elite de Tarraco que aparece en una de las caras de una placa de mármol opistógrafa de Tarragona ${ }^{25}$ junto a una dedicatoria honorífica a Pompeyo, que data del año 71 a. C, en la otra cara $^{26}$. P. Mucius Scaevola pertenecía a una familia bien conocida de la Roma republicana (López Vilar 2013 a 180 y 2103b, 440-441), y ocupó un papel importante en el bando cesariano una vez concluida la batalla de Ilerda, tal y como atestigua la erección de una estatua en su honor en el foro

24 Aunque el propio López Vilar indica que existen diversos testimonios epigráficos de soldados de nomen Scaeva que se pueden encuadrar cronológicamente a lo largo del siglo I d. C. y que Mommsen consideró que el nombre de la unidad Ala Scaeva le fue dado en honor del centurión Marcus Cassius Scaeva, mencionado por César.

25 CIL I, 2964b=CIL II ${ }^{14}$ 2, 998 (Tarraco/ Tarragona): P(ublio) Mucio [fil(io)]/ Scaevo[lae].

26 CIL I, 2964a=CIL II ${ }^{14}$ 2, 991 (Tarraco/Tarragona): [Cn(aeo) Po]mpe[io] [Cn(aei) f(ilio)] / [Ma]gn(o) $\operatorname{Im}[p$ (eratori) iter(um)].

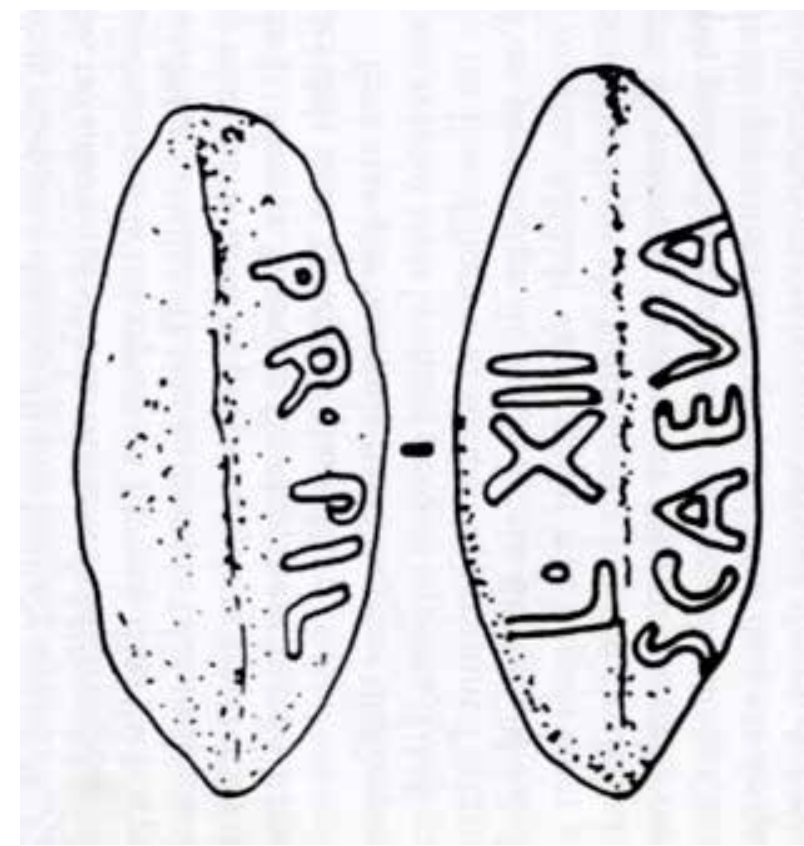

Figura 13. Glans inscripta con leyenda: LXII/PR PIL proveniente de Peruggia. Según Keppie, 1998, p. 124.

tarraconense, sustituyendo, nada menos, que a la de Pompeyo y reutilizando la placa del pedestal (Ruiz de Arbulo, 2002, 137-156; Alföldy 2000, 9) ${ }^{27}$. Por su parte, López Vilar señala que la datación de la inscripción coincidiría grosso modo con la de los lotes de balas de Prades y Picamoixons, por lo que apuesta por la participación de P. Mucius Scaevola, como alto oficial bajo las órdenes de César, en los inicios del Bellum Hispaniense (López Vilar, $\left.2013^{\mathrm{a}}, 181\right)^{28}$. Ahora bien, a nuestro juicio, existen indicios para asociar preferentemente la leyenda $S C A E$ con el centurión Scaeva, más que con el

27 Alföldy optó por considerar a P. Mucius Scaevola como un legado de César, no obstante, Ruiz de Arbulo considera que Scaevola habría recibido del mismo César el encargo de dirigir la fundación de la colonia tras constituirse Tarraco bajo el nombre de Colonia Urbs Triumphalis Tarraconensis. De la misma manera, este personaje habría sido responsable directo del asentamiento de los veteranos legionarios procedentes de los licenciamientos producidos tras la derrota de las tropas pompeyanas en la batalla de Ilerda. A pesar de haber sido César el fundador oficial de la Colonia, parece que P. Mucius Scaevola pudo ser el "brazo ejecutor" de su general.

28 Destaca que la presencia de monedas asociadas al lote de glandes de Picamoixons refuerza la relación de las balas con el bando cesariano, dado que buena parte de las tropas de César procedían de la Galia Narbonense y parte de ellas se habían entretenido en el asedio de Marsella. 
magistrado Scaevola de la inscripción tarraconense. En primer lugar, como hemos visto en el caso de la lectura Q(uinctus) Cae(cilius), cuando aparecen los nomina de un personaje perteneciente a la elite política y militar de la República, es más común que aparezca el gentilicio o uno de ellos, y no el cognomen, excepción hecha de los pompeyanos que se "acogen" al apelativo Magnus, perfectamente conocido por sus contemporáneos, y más breve para reflejar en un soporte de dimensiones reducidas. En segundo lugar, creemos que si se tratara del magistrado- legado según Alfoldy-Mucius Scaevola, se habría utilizado una abreviatura diversa de $S C A E$ a fin de diferenciarse de Scaeva. Por último, cabe mencionar, que, muy probablemente, el hecho de que el cognomen de un centurión conocido de César aparezca en balas de Italia e Hispania, se debe seguramente a un afán propagandístico del general romano; volveremos sobre esta cuestión más adelante para tratar de afinar un poco más sobre la contextualización de las glandes y la identificación de la leyenda.

NUEVAS CONSIDERACIONES SOBRE LA MARCA SCAE: LA LEYENDA SCAE EN EL TEATRO DE OPERACIONES DEL BELLUM HISPANIENSE.

A la luz de las propuestas comentadas, las glandes con leyenda $S C A E$ podrían adscribirse al bando cesariano en la Guerra Civil, lo que per se es ya una novedad en el contexto de los ejemplares datados en este período. Ahora bien, el hallazgo que aquí presentamos introduce cierto ruido en la propuesta de López Vilar. Este investigador asocia las glandes estudiadas a diversos momentos de la batalla de Ilerda. Así, los hallazgos de Prades y Picamoixons, corresponderían, por cercanía, con el lugar de la batalla, a depósitos abandonados en una huida en el contexto táctico de la misma, mientras que las de Monzón, más alejadas del territorio nuclear del conflicto, han sido interpretadas como signos de escaramuzas posteriores de las mismas tropas (López Vilar, 2013a, 181). Hasta ahora, las apariciones documentadas de lotes con la marca $S C A E$ se distribuían en un área geográfica relativamente homogénea del área catalano-aragonesa, por tanto era posible su asociación al ámbito geo-estratégico de la campaña de Ilerda. En este contexto, ¿cómo explicar la presencia de uno de estos proyectiles en Huete, a más de $450 \mathrm{~km}$ de cualquiera de los enclaves mencionados? Para tratar de responder este interrogante, se hace necesaria una revisión de la interpretación de las piezas documentadas poniéndolas en correlación con los datos conocidos sobre las campañas y recorridos de tropas en el Bellum Hispaniense.

Como apunta López Vilar, en la medida en que el hallazgo de Picamoixons podría situarse en el siglo I a. C, sin más detalle, la marca $S C A E$ habría de asociarse a las guerras sertorianas o bien a la de César y Pompeyo. Sin embargo las glandes de Prades, donde aparece claramente la vinculación entre las leyendas $X I I$ y $S C A E$, permiten asignar por analogía, ambos lotes de balas al Bellum Hispaniense. Así, el contexto debería ser la batalla de Ilerda, en la que sabemos que César contaba con unidades de honderos. A pesar de que no duda de la vinculación de las balas con dicha batalla, el autor afirma que no tenemos constancia de la presencia de proyectiles de honda, y menos con inscripción, en el lugar atribuido al escenario del combate (López Vilar, 2013 182 y 2103b, 444-445). Aduce que esta ausencia de proyectiles puede deberse a que los grupos de honderos hubieran actuado más en zonas de montaña, o bien a la falta de hallazgos. En este sentido dice tener noticias de nuevos hallazgos de balas con inscripción en la Granja d' Escarp (Lleida), en un lugar mucho más próximo al escenario de la batalla, concretamente a $10 \mathrm{~km}$ al oeste donde tradicionalmente se ha ubicado (Schulten, 1940, mapa 1). Habrá que tener en cuenta para el futuro estas noticias de cara a la interpretación de la inscripción $S C A E$.

$\mathrm{Si}$ asumimos como válida la lectura unitaria de $S C A E$ y la pertenencia de las piezas con esta leyenda a la guerra civil entre César y Pompeyo, resta hallar un contexto dentro del Bellum Hispaniense en el que pudiese encajar la presencia de este tipo de balas en el área de Huete (Cuenca) que no tiene por qué ser incompatible con la vinculación de las piezas a la batalla de Ilerda, pero sí elimina, al menos, la exclusividad de esta asociación: no todas pertenecerían a esta fase de las guerras civiles. Por otra parte, no debemos descartar las asociaciones de la marca $S C A E$ con Mucio Escévola, ni con el centurión cesariano Scaeva. Una de las posibilidades objetivas, es tratar de rastrear los pasos de la Legio XII tras la batalla de Ilerda. Sabemos que dicha legión fue reclutada por el mismo César en el año 58 a. C y que combatió bajo su mando en la Guerra de las Galias, con participación decisiva en campañas importantes como la de los Nervios. Una vez resultó victorioso, la legión acompañó a César 
a la campaña de Ilerda en el verano del año 49 a. C. El problema es que, una vez que finalizó la campaña, la XII retornó a Italia con César y no volvería a pisar Hispania (Rodríguez González, 2003, 320322). Terminadas las operaciones bélicas en la Citerior, César decidió perdonar y licenciar al resto de tropas vencidas de los legados pompeyanos, Afranio y Petreyo, y enviarlas hasta el río Var, en las proximidades de Niza. A las legiones derrotadas les acompañaron, precediéndoles en el camino, dos legiones cesarianas, posiblemente la XII fuera una de ellas. Una vez llegaron al río, fue licenciado el resto del ejército pompeyano y, presumiblemente las dos legiones cesarianas comenzasen a preparar el sitio de Marsella (Bell. Hisp. 1, 86-87). Tenemos constancia de que César marchó hacia Corduba y después a Gades entre Agosto y septiembre del año 49 a. C (Bell. Hisp. 2, 20, 2), tras una breve estancia en las dos ciudades béticas, volvió a partir, esta vez por mar, desde Gades, hacia Tarraco, donde llegaría el 1 de Octubre del mismo año 49 a. C (Bell. Hisp. $2,21,4-5)$. Posteriormente se dirigió por tierra a Narbona, y, desde allí, hacia Marsella para concluir el asedio de la ciudad rebelde (Bell. Hisp. 2, 21, 5). Marsella se habría rendido parece que hacia el 10 de Octubre, aunque no se pueden considerar las fechas como seguras, y César llegó el día 25 del mismo mes. Cumplidas las condiciones de la rendición, dejó dos legiones de guarnición en la ciudad y partió con el resto hacia Italia, en pos de Pompeyo (Bell. Hisp. $2,22,5-6)$. Sin embargo, el relato del corpus cesariano no especifica qué legiones dejó en Marsella. Lo más probable es que la Legio XII marchara con César hacia Italia, una vez vencida la resistencia de Marsella, si es que no partió antes, con ocasión de la victoria en Ilerda. Por lo tanto, por esta parte no contamos con ningún movimiento de la Legio XII que nos acerque a Huete. La única posibilidad sería que acompañase a César en su viaje a la Bética en Agosto del año 49, o bien que el propio César hubiese dejado una vexillatio de la misma legión en Hispania pero no tenemos constancia de que fuera así en ningún caso.

A no ser que una vexillatio de la XII con un contingente de honderos hubiese permanecido en la Península, hemos de descartar la posibilidad de cualquier paso de la Legión XII por Huete en el contexto de la campaña de Ilerda. Ello nos obliga a plantearnos la necesidad de ampliar el espectro de datación de las piezas con leyenda $S C A E$ a otros momentos de la guerra civil. En el año 48 a. C se desarrollan las operaciones fundamentales para el desenlace de la guerra: incluida la célebre batalla de Pharsalos, en la que tenemos constancia de la participación de la Legio XII. Una vez derrotado Pompeyo Magno, César no volvería a Hispania hasta el año 45 a. C, para sofocar la rebelión de Cneo Pompeyo. Ya muerto César, en el año 44 a. C, sus legados en Hispania, dirigidos desde Roma por Antonio y Octaviano, tratarían de hacer lo propio con el último levantamiento en Hispania protagonizado por el hijo mayor de Pompeyo: Sexto.

Los últimos enfrentamientos entre cesarianos y pompeyanos y la huida de Sexto Pompeyo desde la Bética hacia la Citerior, podrían ser un contexto plausible para el lote de proyectiles aquí presentado. No obstante, la Legio XII no regresaría a Hispania, tras la campaña de Ilerda, por ello habríamos de pensar, si tomamos como válida la asociación de los proyectiles a la legión, en una reutilización de munición originaria de la $L e$ gio XII por parte de los funditores de unidades militares que habían permanecido en Hispania al mando de los legados cesarianos tras la batalla de Munda. Según relata Dión Casio, Sexto Pompeyo, aprovechando la muerte de César y el desconcierto creado, huyó desde Corduba, hasta la Lacetania, perseguido por tropas cesarianas. Una vez allí, aglutinó un ejército en torno a sí, con elementos de las tribus locales de la Lacetania y supervivientes de Munda, para volver a emprender camino hacia la Bética, dónde los apoyos al bando Pompeyano aún eran numerosos, con el fin de oponerse desde Hispania a los sucesores de César (Dion. Cas. 45, 10). El relato de Dion Casio no proporciona detalle alguno acerca del itinerario del Sexto en su camino hacia Lacetania, situada en el área septentrional de la actual provincia de Aragón, al pie de los Pirineos, limitando con los ausetanos (Beltrán Lloris, 2001). A pesar de que la falta de datos no permite más que aventurar esta hipótesis, es posible, aunque poco probable, que Sexto Pompeyo atravesara la comarca de Huete en su camino para alcanzar el país de los lacetanos. Un repaso al panorama viario de la Hispania del siglo I a. C podría sugerir alguna posibilidad que apoyase la hipótesis antes expuesta, sin embargo, la escasez de datos no permite aventurar un itinerario concreto, pues la vía empleada para marchar desde la Ulterior, concretamente desde la Bética, hasta la Citerior, no pasaba por la zona central de la Península, sino que corría a lo largo de la costa mediterránea, preludiando el trazado de 
la Via Augusta. Conocemos dos grandes vías de origen militar, que estaban plenamente operativas desde antes de fines del siglo II a. C: la futura Via Augusta, que partía desde Gades, cruzaba la Bética y recorría toda la costa levantina hasta la Galia Narbonense, y el otro gran eje, ya en la Citerior, que comunicaba la costa con la zona interior del Valle del Ebro pasando por Ilerda. Estas vías que originariamente se emplearon para transporte de tropas, rápidamente se convirtieron en las arterias de la expansión comercial de Hispania en el siglo I a. C (Díaz Ariño, 2009, 115-152; Mayer y Roda, 1986, 157-170).

LA LEYENDA SCAE: OTRAS POSIBILIDADES DE INTERPRETACIÓN: HACIA UN PERSONAJE HISTÓRICO.

Una vez considerados los principales condicionantes para situar en el espacio y el tiempo las balas con marca $S C A E$, creemos conveniente volver sobre una última consideración que podría dotar de sentido a la identificación de las balas con el centurión Scaeva mencionado anteriormente, y apoyar la tesis de contextualización en el marco del Bellum Hispaniense. A la vista de los datos disponibles, no parece posible situar a la Legio XII y a Marcus Cassius Scaeva, en las operaciones militares del Bellum Hispaniense, más allá, (y sólo quizá) de la batalla de Ilerda; sin embargo, la lectura e identificación de López Vilar nos parecen plausibles. Por otra parte, parece comprobado que la costumbre de acuñar un antropónimo en glandes plúmbeas, estaba vinculado a grandes próceres militares que solían acompañarlo de mensajes y símbolos de cariz propagandístico destinados, por lo que parece, a sus propias tropas. En este marco, la presencia del cognomen de un primipilo, por muy conocido que este fuese (ya hemos referido la mención que el propio César hace de su heroísmo en combate), resulta, cuanto menos, particular y no invita precisamente a apoyar esta identificación.

Sin embargo, no hace mucho, M. Liscovitz, en su tesis doctoral, analiza con detenimiento el modelo de virtus y clementia de la propaganda cesariana en el texto de la Pharsalia de Lucano, que puede aproximarnos a una hipótesis de resolución de este problema (Liscovitz, 2013) ${ }^{29}$. El estudio mencionado reseña que uno de los personajes del texto que encarna el nuevo concepto de "virtus

29 Cf. Liskovitz, para un desarrollo completo de la cuestión que no podemos asumir aquí. cesariana” es, precisamente, la figura del centurión M. Cassius Scaeva. Liscovitz señala cómo Lucano describe, precisamente, al centurión cesariano como: "un arma de carne y hueso" en las manos de César, un ejemplo de lo que significa ser un individuo de César, sólo útil en la medida en que le puede ayudar" (Liscovitz, 2013, 4). Lucano consideró siempre a César como un destructor de los valores republicanos que él mismo decía salvaguardar, y en ocasiones, rescatar. Liscovitz apunta, asimismo, que el propio Lucano da, en su épica, un significado muy concreto a la virtus tradicional romana; un significado que César pervierte para asociar las cualidades positivas con su propia construcción de una nueva identidad romana personificada en individuos como Scaeva (Liscovitz, 2013, 11-12). Se trata de una cuestión compleja vinculada a la historia de las mentalidades, que no podemos desarrollar aquí, pero el empleo de una propaganda de este tipo, personificada en individuos concretos que abrazan a un líder carismático y su causa, y la fama que hubo de adquirir Scaeva, a juzgar por los testimonios de Lucano y el propio César, nos llevan a una posible explicación de la presencia del cognomen de un primipilo en las glandes que aparecen en contextos dispares. Dicha presencia adquiere otra significación teniendo en cuenta que, probablemente, César utilizó al centurión Scaeva como vehículo de su propaganda, asociando los valores de la virtus a su figura. En este sentido, el hecho de inscribir su cognomen, por todos conocido, en las glandes, de manera que la vinculación entre "virtus" y Scaeva quedara reflejada y se difundiese con rapidez, parece una buena manera de dotar de una expresión material relativamente simple a un mensaje complejo. Esta manera de proceder está bien documentada en las glandes inscriptae de diversos caudillos romanos que hemos venido revisando en este trabajo, tanto en el contexto de las guerras sertorianas como en el del propio Bellum Hispaniense. De asumir esta hipótesis, la presencia de la marca $S C A E$ en las glandes de Hispania no tendría por qué relacionarse necesaria y exclusivamente con la Legio XII y su paso por Hispania, ni con la presencia del susodicho centurión (aunque sí debían conocerlo en la campaña de Ilerda); el cognomen se habría convertido en un mensaje propagandístico en la línea de otros conocidos y habría quedado, de algún modo, despersonalizado más allá de su carga ideológica. No sería de extrañar, por tanto, que César se hubiera servido de esta sutil propagan- 
da y que la inscripción $S C A E$, fuese, en efecto, un reflejo de ello. Sin embargo no podemos más que esbozarlo a modo de hipótesis en la esperanza de poder desarrollarla satisfactoriamente en un futuro.

\section{CONCLUSIONES}

En hallazgos como el de Huete, carentes de contexto arqueológico, es preciso tener muy en cuenta la posibilidad de que no todos los ejemplares del conjunto sean del mismo período. Cabe recordar que las piezas son bastante heterogéneas morfológicamente, y su peso medio se aproxima más a los pesajes de los proyectiles documentados recientemente en la II Guerra Púnica que a las piezas datadas en el siglo I a. $C^{30}$. Aun así, existe un número suficiente de argumentos para asumir la contemporaneidad del conjunto y descartar una datación en este período: las noticias sobre el hallazgo, su concentración en un espacio no muy extenso (80 $\mathrm{m} 2$ ), la escasa representatividad del peso medio en un lote tan pequeño, la similitud morfológica de algunos ejemplares anepífrafos con tipos de lotes tardo-republicanos, y, sobre todo, la existencia de una glans inscripta.

Descartada, pues, la opción de la adscripción al período de las Guerras Púnicas, las guerras civiles romanas representan el horizonte cronológico más probable. En dicho contexto, resulta actualmente imposible aplicar parámetros morfológicos ni de pesaje para diferenciar conjuntos de glandes del período sertoriano del cesariano y pompeyano. Los únicos criterios disponibles son los lugares de hallazgo (en relación con la localización de los episodios bélicos de ambos conflictos) y, sobre todo, las inscripciones de algunas de las balas. Si nos centramos en el caso que nos ocupa, no contamos con escenarios bélicos documentados en el Cerro de Alvar-Fáñez ni en las cercanías de Huete, en el $B e$ llum Hispaniense y la posibilidad de paso de tropas por el lugar es remota. Por el contrario, existen evidencias de enfrentamientos armados y paso de

30 Queremos agradecer al Prof. F. Quesada Sanz, de la Universidad Autónoma de Madrid, sus valiosos consejos y aportaciones a lo largo de diversas conversaciones. Comentamos detalladamente la cuestión de los pesos y su importancia para establecer parámetros básicos a fin de diferenciar individuos anepígrafos en lotes de las guerras anibálicas de aquellos de las guerras civiles romanas. Coincidimos con él en la apreciación de que, a pesar de las limitaciones impuestas por lo exiguo del conjunto, los pesos de los proyectiles de Huete son significativamente bajos. tropas en las cercanías de Huete durante el enfrentamiento de Sertorio con el Senado romano.

La lectura del texto epigráfico Q(uinctus) $C$ (aecilius) corroboraría la datación y contextualización del lote de Huete en las guerras sertorianas, pero nosotros hemos optado aquí por la interpretación $S C A E(V A)$ de López Vilar como correcta y la consideramos más probable que la propuesta por Contreras et alii. De ello, sin embargo, resulta una nueva paradoja: el hallazgo de la pieza n. 1 de Huete, no favorece las hipótesis que ha planteado en relación a la leyenda $S C A E$ y la batalla de Iler$d a$, puesto que no se puede explicar la presencia de una bala con la marca $S C A E$ en Huete exclusivamente desde el ámbito geoestratégico de la campaña de Ilerda.

Así las cosas, no estamos en disposición de dotar al lote de Huete de un contexto histórico concreto, ni de vincularlo con una operación específica de la que tengamos noticia en el Bellum Hispaniense. Consideramos que la presencia de la marca $S C A E$ induce a pensar en glandes pertenecientes al bando cesariano, pero los datos disponibles no nos permiten más que sugerirlo. El hallazgo de Huete nos obliga a pensar en nuevas perspectivas y soluciones para contextualizar debidamente este tipo de piezas con inscripción. El problema de la interpretación de estas piezas está aún lejos de ser resuelto y debemos aguardar al descubrimiento y publicación de otros materiales para encontrar una solución definitiva. A pesar de todo, este hallazgo enriquece un mapa de distribución de balas de honda de este tipo en la Península Ibérica. La aparición de los lotes de Picamoixons, Prades, Huete, Monzón y Sanitja, apunta a la existencia de balas de honda plúmbeas pertenecientes a las guerras entre César y los hijos de Pompeyo en la Citerior. Esta presencia no había podido certificarse hasta el año 2006 debido a la ausencia de hallazgos fechables entre el 49 y el 45 a. C fuera del territorio de la Bética. La interpretación de estos conjuntos como probablemente cesarianos es, en sí misma, una hipótesis novedosa que el conjunto aquí presentado podría reforzar. Sin embargo, no hemos de olvidar, tampoco, las motivaciones que pudieron llevar a los generales de los ejércitos de las guerras civiles romanas a emplear las glandes como vehículo propagandístico. A priori, era mucho más necesaria la propaganda y la construcción de legitimidad para los hijos de Pompeyo que para César y sus partidarios, en el contexto de la guerra civil en Hispania. Y así parece demostrar- 
lo la enorme mayoría de glandes encontradas con leyendas y mensajes inequívocamente vinculables a los pompeyanos y sus legiones. De ser, efectivamente, asociable la leyenda $S C A E$ al bando cesariano, el lote de Huete, sería una aportación más a un todavía escaso pero novedoso corpus de balas en la Hispania de época republicana. En este sentido parece reveladora la hipótesis antes expuesta sobre la propaganda cesariana, pero, a nuestro modo de ver, hemos de ser aún muy cautos con las asociaciones, por mucho que algunas evidencias parezcan claras $^{31}$.

\section{Bibliografía.}

Aguado Molina, M; Bango García, C; Jiménez Cañizos, O. (2007), "El hueso trabajado del yacimiento de Alvar-Fáñez (Huete-Cuenca)", Caesaraugusta, 78, 495-551.

Alföldy, G.(2000), "Wann wurde Tarraco römische Kolonie?", Epigraphai. Miscellanea Epigrafica in onore di Lidio Gasperini, (G. Paci, Ed.), Tivoli, 3-22.

Almagro, Basch, M. (1978), Segobriga. Guía del conjunto arqueológico, Madrid.

Almagro Gorbea, M. (1999), "Los íberos en Castilla-La Mancha”, I Jornadas de Arqueología Ibérica en Castilla La Mancha, Iniesta, Cuenca, 1997, 25-48.

Aranegui Gascó, C. (2003), "Proyectiles de honda con epígrafes griegos atribuidos a Sagunto", Romula 2, 43-52.

Beltrán lloris, F. (1990), "La pietas de Sertorio", Gerión, 8, 211-226.

Beltrán Lloris, F. (2001), "Hacia un replanteamiento del mapa cultural y étnico del norte de Aragón”, Religión, lengua y cultura prerromanas de Hispania (VIII CLCP), F. Villar, M. ${ }^{\mathrm{a}}$ P. Fernández Álvarez (Eds.), Salamanca, 61-82.

Benedetti, L. (2013), Glandes Perusinae: Revisione e aggiornamenti. Opuscula Epigraphica del Dipartamento de Scienze dell' Antichità, Sapienza Universitá di Roma, 13, Roma.

Bonet, H. y Mata, C. (2002), El Puntal dels Llops. Un fortín edetano, TV del SIP, 99, Valencia.

Bosman A.V.A.J. (1995), "Pouring lead in the

31 Expresamos nuestro agradecimiento a los Dres. Helena Gimeno Pascual (Directora del Centro CIL II-UAH) y P. Rothenhoefer (de la Kommission für Alte Geschichte und Epigraphik, en Munich) y al Prof. Joan Carbonell Manils (de la Universidad Autónoma de Barcelona) por su ayuda y valiosos consejos en materia epigráfica. pouring rain: making lead slingshot under battle condition", Journal of Roman Military Studies, 6, 99-103.

Bowmann, A.K; Champlin, E; Lintott, A. (Eds.), (1996), The Cambridge Ancient History, X. The Augustan Empire, 43 B.C.-A.D. 69, Cambridge.

Broughton, T.R.S. (1951), The magistrates of the Roman Republic, Vol. I: 509 B.C.-100 B.C., New York.

Casariego, A; Córdoba, A.C; Pliego, F; Cores, G. (Eds.), (1987), Catálogo de plomos monetiformes de la Hispania Antigua, Madrid.

Castelo, R., Torrecilla, A., Aguado, M; Bango, C; Arribas, R; Sierra, C. (2000), "Arqueología en la comarca de la Alcarria conquense. Avance de investigaciones sobre el cerro del yacimiento del cerro de Alvar-Fáñez", Cuadernos de Prehistoria y Arqueología de la Universidad Autónoma de Madrid, 46, 95-149.

Castelo Ruano, R. (2008), "Cerámica ática documentada en el Cerro de Alvar-Fáñez (Huete-Cuenca), cílica de figuras rojas grupo de Viena 116", Cuadernos de Prehistoria y Arqueología de la Universidad Autónoma de Madrid, 34, 77-103.

Coleman, K.M. (1996), “A Left-Handed Gladiator at Pompeii”, ZPE, 114, Bonn, 194-196.

Contreras, F; Müller, R; Valle, F. (2006), “El asentamiento militar romano de Sanitja (123-45 a. C): una aproximación a su contexto histórico”, Mayurqa, 31, 233-249.

Contreras, F; Müller, R; Muntaner, J; Valle, F. (2006-2007), "Estudio pormenorizado de los glandes depositados en el CEHIMO”, Cuadernos de Estudios del CEHIMO, 33, 1-47.

Corzo Sánchez, R. (1973), "Munda y las vías de comunicación del Bellum Hispaniense”, Habis, 4, 241-252.

Díaz Ariño, B. (2005), "Glandes Inscriptae de la Península Ibérica”, ZPE, 135, Bonn, 218-236.

Díaz Ariño, B. (2008), Epigrafía Latina Republicana de Hispania, Col. Instrumenta, Barcelona.

Díaz Ariño, B. (2009), "La Hispania Citerior, desarrollo económico e integración en época republicana: una aproximación epigráfica”, Dialogues d'histoire ancienne, vol. 35, n. 1, 115-132.

Domergue, C.(1970), "Un temoignage sur l'industrie miniere et metallurgique du plomb dans la region d'Azuaga (Badajoz) pendant la guerre de 
Sertorius”, Actas del XI Congreso Nacional de Arqueología (Mérida, 1968), Zaragoza, 608625.

Domínguez, Arranz, A. y Maestro Zaldívar, E. (2002), La Vispesa: foco de romanización de la Ilergecia occidental, Instituto de estudios Altoaragoneses, Diputación de Huesca, Binéfar.

Domínguez Monedero, A.J. (2005), "Los mercenarios baleáricos”, Treballs del Museu Arqueologic d'Eivissa de Formentera, 56, 163-189.

Fontenla Ballesta, S. (2005), "Glandes de honda procedentes de la batalla de Asso", Alberca: Revista de la Asociación de Amigos del Museo Arqueológico de Lorca, 3, 67-84.

Feugère. M. (2002), "Les instruments de chase, de pesque et d'agriculture", Recherches sur l'Economie vivrière des Lattarenses, Lattara 5, M. Py (Ed.), Lattes, 139-162.

García, M. y Lalana, M. (1991), “Algunos glandes de plomo con inscripciones latinas y púnicas hallados en Hispania”, Acta Numismática, 21, pp. 101-108.

Greep, S.J. (1987), "Lead Sling-shot from Winddridge farm, St. Albans and the Use of the Sling by the Roman Army in Britain”, Britannia 18, 183-200.

Griffith, W.B. (1989), "The Sling and its Place in the Roman Imperial Army", Roman Military Equipement: the sources of evidence. British Archaeological Reports Intern, 476, Van driel-Murray (Ed.), Oxford, pp. 255-279.

Henry, B. M. (1976), "Les balles de fronde etrusques en plomb”, 101 Congrés Nat des Societés Savantes (Lille, 1976), Paris, 9-19.

Henry, B.M. (1975-1976), "La fronde chez les Celtes. Les projectiles et leur utilisation”, Bulletin $d u$ Centre de Recherches et d'Enseignement de l'Antiquité, Angers 2,17-24.

Hubrecht, A.V.M. (1964), "The use of the sling in the Balearic Islands", Bulletin Antieke Beschaving, 39, 92-93.

Keppie, L. (1988), The making of the Roman Army: from Republic to Empire, Oklahoma.

López Vilar, J. (2013a), "Glandes Inscriptae a l'Ager Tarraconensis”, Homenaje a G. Alföldy, ICAC, Tarragona, 175-184.

López Vilar, J. (2013b) "César contra Pompeyo. Glandes Inscriptae de la batalla de Ilerda", Chiron, 43, 432-457.

Mayer, M. y Roda, I. (1986), "La epigrafia republicana en Cataluña, su reflejo en la red viaria”, $A c$ - tas de la Reunión sobre Epigrafía Hispánica de época romano-republicana (Zaragoza, 1983), Institución Fernando el Católico, Zaragoza, 157-170.

Monti Di, J. C. G. y Gómez, M. J. B. (2004), “La minería romana del Lapis Specularis una minería de interior", Investigaciones arqueológicas en Castilla La Mancha, Junta de Comunidades de Castilla-La Mancha, 1996-2002, 245-256.

Moralejo Ordax, J. (2011), El armamento y la táctica militar de los galos. Fuentes literarias, iconográficas y arqueológicas, VitoriaGasteitz.

Moret, P. (1996), Les fortifications ibériques de la fin de l'Âge du Bronce à la conquête romaine, Casa de Velázquez, Madrid.

Nicolás, J.C. de (1983), Romanización de Menorca, Menorca.

Nuñez- Pariente de León, E. y Quesada Sanz, F. (2000), "Una sepultura con armas de Baja época ibérica (o época Romana Republicana) en la necrópolis del 'Cerro de las Balas' (Écija, Sevilla)”, Gladius XX, 191-220.

Osuna, Ruiz, M. (1997), "Ercávica. Las ciudades romanas de la provincia de Cuenca”, Homenaje a Francisco Suay, Arqueología Conquense, XIV, Cuenca, 169-208.

Pemán, C. (1988), "Nuevo ensayo de interpretación de la topografía del Bellum Hispaniense”, Homenaje a A. García y Bellido, vol. V, Madrid, 36-80.

Pina Polo, F y Zanier W. (2006),"Glandes Inscriptae procendentes de la Hispania Ulterior", Archivo Español de Arqueología, 79, 29-50.

Puig i Cadafalch, F. (1911-1912),"Troballa d'armes i restes de maquines de guerra a Empúries”, AIEC 4, 671-672.

Quesada Sanz, F. (1992), El armamento ibérico. Estudio tipológico, geográfico, funcional, social y simbólico de las armas de la Cultura Ibérica (siglos VI-I a. C.) Monographies Instrumentum, 3, Montagnac.

Quesada Sanz, F. (2008), “Armanento romano e Ibérico en Vrso (Osuna). Testimonio de una época”. Cuadernos de los Amigos de los $\mathrm{Mu}$ seos de Osuna, 10, 13-19.

Le Roux, P. (1997), "Glandes ou balles de fronde”, Antiquités de l'Espagne (P. Rouillard, Ed,), Paris. Musée du Louvre, Musée des Antiquités Nationales de Saint-German-en-Laye, 68-70. 
Liscovitz, M. (2013), Virtus, Clementia and Caesar's Left-Hand Man: Lucans Lament of Republican Ethics, (Haverford College), Pennsylvania.

Rodríguez González, J. (2003), "Historia de las legiones romanas, Madrid.

Ruíz, A; Bellón, J.P; Molinos, M; Gómez, F. (2011), "La sombra de los hombres: la Batalla de Baecula (208 a.n.e.)", Miti di guerra, riti di pace. La guerra e la pace: un confronto, interdisciplinare, C. Masseria y D. Loscalzo (Eds.), Bari.

Ruiz de Arbulo, J. (2002), "La fundación de la Colonia Tarraco y los estandartes de Cés”, Valencia y las primeras ciudades romanas en Hispania, (A. Jiménez et al., Coords.) Valencia, 137-156.

Schulten, A. (1940), Fontes Hispaniae Antiquae, vol. $V$, Barcelona.

Stylow, A.U. (2005),"Fuentes epigráficas para la historia de la Hispania Ulterior en época republicana”, Julio César y Corduba: tiempo y espacio en la campaña de Munda (49-45 a.C.) (E. Melchor Gil, J. Mellado Rodríguez y J.F. Rodríguez Neila (eds.), Córdoba, 247-262.

Villaronga, L. (1983), "Diez años de novedades en la numismática hispano-cartaginesa, 1973-1983”, Studi di numismatica punica. Rivista di Studi Fenici, XI, 57-73.

Völling, T. (1990), "Funditores im Römischen Herr”, Saalburg Jährbücher, 45, 24-58.

Zagenmeister, C. (1885), Glandes Plumbeae latinae inscriptae, Ephemeris Epigraphica VI, Berlin.

Zarzalejos Prieto, M. (2004), “Terra Sigillata procedente de la Cueva de los Cabañiles (Huete, Cuenca)", Cuadernos de Prehistoria y Arqueología de la Universidad Autónoma de Madrid, (A. Morillo Cerdán, Coord.), Madrid, 159-182.

RECURSOS ELECTRÓNICOS.

CIL II www. 2uah.es/imagines_cilii (epigrafía de Complutum). 